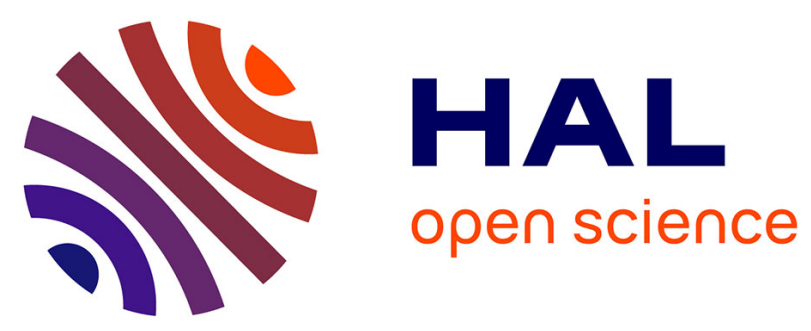

\title{
Thermoinduced Crystallization-Driven Self-Assembly of Bioinspired Block Copolymers in Aqueous Solution
}

\author{
Zhiwei Wang, Min Lin, Colin Bonduelle, Rongye Li, Zhekun Shi, Chenhui
}

Zhu, Sébastien Lecommandoux, Zhibo Li, Jing Sun

\section{To cite this version:}

Zhiwei Wang, Min Lin, Colin Bonduelle, Rongye Li, Zhekun Shi, et al.. Thermoinduced Crystallization-Driven Self-Assembly of Bioinspired Block Copolymers in Aqueous Solution. Biomacromolecules, 2020, 21 (8), pp.3411-3419. 10.1021/acs.biomac.0c00844 . hal-02934927

\section{HAL Id: hal-02934927 \\ https://hal.science/hal-02934927}

Submitted on 24 Dec 2020

HAL is a multi-disciplinary open access archive for the deposit and dissemination of scientific research documents, whether they are published or not. The documents may come from teaching and research institutions in France or abroad, or from public or private research centers.
L'archive ouverte pluridisciplinaire HAL, est destinée au dépôt et à la diffusion de documents scientifiques de niveau recherche, publiés ou non, émanant des établissements d'enseignement et de recherche français ou étrangers, des laboratoires publics ou privés. 


\title{
Thermoinduced Crystallization-Driven Self-Assembly of Bioinspired Block Copolymers in Aqueous Solution
}

\author{
Zhiwei Wang," Min Lin," Colin Bonduelle, Rongye Li, Zhekun Shi, Chenhui Zhu, \\ Sébastien Lecommandoux,* Zhibo Li, * and Jing Sun*
}

Cite This: Biomacromolecules 2020, 21, 3411-3419

\begin{abstract}
Delicate control over architectures via crystallization-driven self-assembly (CDSA) in aqueous solution, particularly combined with external stimuli, is rare and challenging. Here, we report a stepwise CDSA process thermally initiated from amphiphilic poly $(N$-allylglycine $)-b$-poly $(N$ octylglycine) (PNAG- $b$-PNOG) conjugated with thiol-terminated triethylene glycol monomethyl ethers ((PNAG- $\left.\left.g-E_{3}\right)-b-P N O G\right)$ in aqueous solution. The diblock copolymers show a reversible thermoresponsive behavior with nearly identical cloud points in both heating and cooling runs. In contrast, the morphology transition of the assemblies is irreversible upon a heatingcooling cycle because of the presence of a confined domain arising from crystalline PNOG, which allows for the achievement of different nanostructured assemblies by the same polymer. We demonstrated that the thermoresponsive property of PNAG- $g-E_{3}$ initiates assembly kinetically that

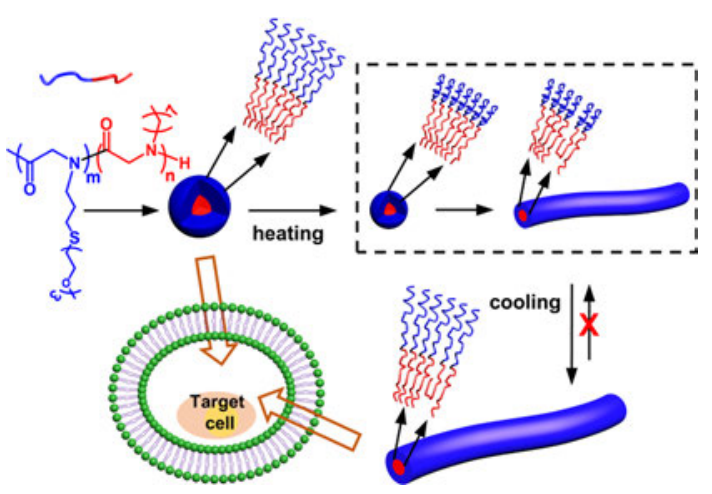
is subsequently promoted by crystallization of PNOG thermodynamically. The irreversible morphology transition behavior provides a convenient platform for comparing the cellular uptake efficiency of nanostructured assemblies with various morphologies that are otherwise similar.
\end{abstract}

\section{INTRODUCTION}

Biological organisms fabricate elegant architectures with remarkable performance through a bottom-up assembly process. $^{1-4}$ The assembly mechanism underlying such a dynamic process is often complex and remains a challenging question. Typically, several environmental factors are combined in a single biological event. For instance, spider dragline silk production is accompanied by a structural transition regulated by sequential $\mathrm{pH}$ variations. ${ }^{5}$ In recent years, block copolymers obtained by a comparatively simpler synthetic approach represent ideal building blocks for the design of bioinspired structures despite less delicacy and control. Particularly, block copolymers containing a crystalline core, such as polyferrocenyl dimethylsilane, polyethylene, and polythiophene can induce crystallization-driven self-assembly (CDSA), a strategy that has offered a higher level tunability on the structure and kinetic process as compared to other selfassemblies. $^{6-12}$ A couple of biocompatible copolymers including poly(2-isopropyl-2-oxazoline) and poly(L-lactide) segments have already been used in the CDSA strategy, which benefits biomedical applications. ${ }^{13-19}$ However, challenges of their controlled fabrication, in particular combined with other assembly processes involving stimuli-responsive features, represent an important limitation. To conceive such a well-defined architecture, motifs with excellent tunability on both chemical structures and functionalities are desired.
Bioinspired peptide-based polymers have been reported as the most explored building blocks for the formation of a hierarchical biomimetic architecture. ${ }^{20-22}$ Their structural isomers, namely, polypeptoids, offer a flexible backbone, simplified molecular interactions, and controllable fabrication over architectures, and have emerged as promising selfassembly motifs for de novo hierarchical structures. ${ }^{23-27}$ In particular, polypeptoids with alkyl groups exhibit a tunable semicrystalline behavior that differs from polypeptides. ${ }^{28-33}$ For example, in a previous report on a block copolypeptoids, the thermoresponsive poly $(N$-( $n$-propyl)glycine $)$ block serves as a crystallizable micellar core with a soluble poly $(N-$ methylglycine) shell as the temperature increases above the cloud point temperature. ${ }^{33}$ Instead, the hydrophobic $\operatorname{poly}(\mathrm{N}$ alkylglycine) with longer alkyl groups is known to arrange in a rectangular crystalline lattice. ${ }^{31}$

It is generally accepted that water is unfavorable for the CDSA. $^{34}$ A couple of solutions have been addressed, for example, an increasing chain length of hydrophilic segments or

Received: June 2, 2020

Revised: July 5, 2020

Published: July 28, 2020 
addition of cosolvents. ${ }^{14,15,17}$ However, cosolvent methods employ organic solvents that limit the potential for biomedical application; while increasing the chain length of hydrophilic segments generally disfavors the organization of a crystalline core for further assembly because of the strong repulsion of long hairy shells. Herein, to tackle these limitations, we designed a new type of block copolymer, a poly $(N$ allylglycine)- $b$-poly(N-octylglycine) (PNAG- $b$-PNOG) diblock copolypeptoid conjugated with thiol-terminated triethylene glycol monomethyl ethers ((PNAG- $\left.g-E_{3}\right)-b$-PNOG). The aim of such a design is to embed long hydrophilic PNAG-g$\mathrm{EG}_{3}$ segments with a lower critical solution temperature (LCST) behavior in a crystalline block copolymer, by which the thermostimulus triggers the collapse of hydrophilic chains to facilitate the ordered fabrication of the crystalline PNOG block upon heating. The obtained diblock copolymers exhibit a reversible thermoresponsive behavior with nearly the same cloud points (CPs) during the heating and cooling runs in aqueous solution. Instead, the morphology transition of the assemblies is irreversible upon a heating-cooling cycle that results in different morphologies by the same copolymer. By taking this advantage, we performed cellular uptake experiments using three types of cells on both spherical and cylindrical constructs wherein the surface chemistry remained similar. We demonstrate that the copolymers formulated in cylindrical assemblies are initially internalized to a greater extent than those in the spherical ones and eventually reach a comparable value.

\section{EXPERIMENTAL SECTION}

Materials and Methods. Tetrahydrofuran (THF), dichloromethane (DCM), and hexane were first purified by purging with dry $\mathrm{N}_{2}$, followed by passing through a column of activated alumina. Glyoxylic acid monohydrate (98\%), allylamine (98\%), octylamine (98\%), benzylamine (99\%), di-tert-butyl decarbonate $\left(\mathrm{Boc}_{2} \mathrm{O}\right)(97 \%)$, and 2,2-dimethoxy-2-phenylacetophenone (DMPA) were purchased from Aladdin Reagent. All other chemicals were purchased from commercial suppliers and used without further purification unless otherwise noted. ${ }^{1} \mathrm{H}$ NMR spectra were recorded on a Bruker AV500 FT-NMR spectrometer. Gel permeation chromatography (GPC) analysis was conducted using an SSI pump connected to a Wyatt Optilab DSP with $0.02 \mathrm{M} \mathrm{LiBr}$ in DMF as the eluent at a flow rate of $1.0 \mathrm{~mL} / \mathrm{min}$ at $50{ }^{\circ} \mathrm{C}$. All GPC samples were prepared at concentrations of $5-10 \mathrm{mg} / \mathrm{mL}$. Conventional calibrations were performed using polystyrene (PS) standards. Differential scanning calorimetry (DSC) studies were conducted using a TA DSC Q20 calorimeter under nitrogen. Powder samples enclosed in aluminum pans were heated from -40 to $200{ }^{\circ} \mathrm{C}$ at $10{ }^{\circ} \mathrm{C} / \mathrm{min}$ for three cycles. Cloud point measurements of aqueous solutions of diblock copolymers ( 1 wt \%) were conducted using a HITACHI U-2900 UV-vis spectrophotometer equipped with a Thermo/Neslab RTE-7 refrigerated bath circulator for temperature control. The experimental temperature range was $25-75{ }^{\circ} \mathrm{C}$ and all $\mathrm{UV}-$ vis absorptions were referenced against distilled water. The temperature at 50\% UV-vis transmittance $(\lambda=500 \mathrm{~nm})$ is defined as the cloud point. Atomic force microscopy (AFM) studies were conducted using tapping mode AFM (Bruker Multimode 8 AFM/SPM system) in ambient air with Nanoscope software with probes acquired from Bruker probes. A volume of the polymer solution $(\sim 10 \mu \mathrm{L})$ was drop-deposited and dried on freshly cleaved mica under ambient conditions for $24 \mathrm{~h}$ before AFM imaging. Minimal processing of the images was done using NanoScope Analysis software from Bruker. Transmission electron microscopy (TEM) experiments were conducted on a FEI TECNAI 20, with a Gatan digital camera and analyzed using Gatan Digital Micrograph software. Samples were prepared on holey carboncoated 200 mesh copper grids. The polymer solution $(6 \mu \mathrm{L})$ was pipetted onto the carbon-coated side. The grids were then blotted to remove the excess solution and then negatively stained with $0.5 \mathrm{wt} \%$ uranyl acetate. The solvent was evaporated under ambient conditions. Confocal laser scanning microscopy (CLSM) images were recorded on a Nikon C2 plus (Nikon Corporation, Japan). Solution small-angle $\mathrm{X}$-ray scattering (SAXS) experiments were performed at the Center de Recherche Paul Pascal (CRPP) in Bordeaux using a highresolution Xeuss 2.0 X-ray spectrometer from Xenoxs operating at $8.04 \mathrm{keV}$. Two-dimensional (2D) scattering patterns were collected using a Pilatus $300 \mathrm{~K}$ Dectris detector and the beam center position and the angular range were calibrated using a silver behenate standard sample. Finally, the two-dimensional SAXS patterns were radially averaged to obtain the one-dimensional scattering profiles.

Synthesis of Poly(N-allylglycine)-b-poly(N-octylglycine) Diblock Copolymers. The $\mathrm{N}$-allyl $\mathrm{N}$-carboxyanhydride (Allyl-NCA, $\mathrm{M}_{1}$ ) and $\mathrm{N}$-octyl $\mathrm{N}$-carboxyanhydride (Oct-NCA, $\mathrm{M}_{2}$ ) monomers were synthesized following a published procedure. ${ }^{35}$ All of the diblock copolypeptoids were synthesized by benzylamine-initiated ringopening polymerization of the corresponding $\mathrm{N}$-substituted $\mathrm{N}$ carboxyanhydrides in a sequential manner. In a representative procedure, allyl-NCA ( $508.1 \mathrm{mg}, 3.6 \mathrm{mmol}, 0.4 \mathrm{M}$ ) was dissolved in anhydrous THF in a glovebox. A stock solution of benzylamine $\left(255.0 \mu \mathrm{L}, 24.0 \mu \mathrm{mol}, 94.2 \mathrm{mM},\left[\mathrm{M}_{1}\right]_{0} /\left[-\mathrm{NH}_{2}\right]_{0}=150: 1\right)$ was added. The polymerization was performed under a $\mathrm{N}_{2}$ atmosphere at $50{ }^{\circ} \mathrm{C}$ for $24 \mathrm{~h}$ and monitored by FTIR until the characteristic peaks of allyl-NCA disappeared. A solution of Oct-NCA in THF $(1.8 \mathrm{~mL}$, $\left.0.7 \mathrm{mmol}, 0.4 \mathrm{M},\left[\mathrm{M}_{1}\right]_{0} /\left[\mathrm{M}_{2}\right]_{0} /\left[-\mathrm{NH}_{2}\right]_{0}=150: 30: 1\right)$ was then added to the above mixture and allowed to stir at room temperature for another $24 \mathrm{~h}$ to reach full conversion. The sample solution was precipitated into excess ether. The polymer was collected by filtration and washed with ample hexane followed by drying under vacuum (340.0 $\mathrm{mg}, 72.0 \%$ yield). The composition of the polymer was determined using end-group analysis by ${ }^{1} \mathrm{H}$ NMR spectroscopy. The number-average degree of polymerization (DP) of each block was calculated based on the integration ratios of characteristic proton peaks of individual blocks.

Synthesis of Poly(N-allylglycine)-b-poly(N-octylglycine) Modified with Thiol-Terminated Triethylene Glycol Monomethyl Ether. Thiol-terminated diethylene glycol monomethyl ethers $\left(\mathrm{OEG}_{3}-\mathrm{SH}\right)$ were synthesized using relative oligo(ethylene glycol) monomethyl ethers according to literature procedures. ${ }^{36}$ Typically, $\mathrm{PNAG}_{142}-b$ $\mathrm{PNOG}_{23}(300.0 \mathrm{mg})$ and DMPA $(16.0 \mathrm{mg})$ were dissolved in DMF. Then $\mathrm{OEG}_{3}-\mathrm{SH}(1.4 \mathrm{~mL},[-\mathrm{SH}] /[-\mathrm{C}=\mathrm{C}]=5)$ was added. The reaction mixture was degassed through three freeze/thaw/pump cycles before being irradiated with UV light at room temperature for 4 $\mathrm{h}$. The mixture was then dialyzed against Millipore water for 3 days and lyophilized to yield (PNAG-g-EG 3$)_{142}-b-\mathrm{PNOG}_{23}$ as a white powder $(473.0 \mathrm{mg}$, $68.0 \%$ yield). All of the other copolymers were modified in a similar way.

Preparation of Polymer Solutions. The block polymer was dispersed in water at a desired concentration in a clean vial. The solution was stirred at room temperature for 5 days, after which the solution was heated to $60{ }^{\circ} \mathrm{C}$ and held at the temperature for $2 \mathrm{~h}$. Then the solution was cooled to room temperature naturally.

Cellular Uptake. The fluorescein isothiocyanate (FITC)-labeled polymer was prepared by the following procedure. (PNAG-g-EG $)_{142^{-}}$ $b$ - $\mathrm{PNOG}_{23}(20.0 \mathrm{mg})$, diisopropylethylamine $(10.0 \mu \mathrm{L}, 0.06 \mathrm{mmol})$, and FITC $(1.0 \mathrm{mg})$ were dissolved in $2 \mathrm{~mL}$ of DMF, followed by stirring at room temperature in the dark overnight. The product was dialyzed with DMSO and then deionized water for a few days to remove the unreacted fluorescent dye and lyophilized. Cells were seeded in a 96-well plate with a density of 5000 cells per well. The plate was then incubated in a humidified $5 \% \mathrm{CO}_{2}$ in air incubator at $37{ }^{\circ} \mathrm{C}$ for $24 \mathrm{~h}$. Then, $100 \mu \mathrm{L}$ of fresh culture medium replaced the original medium, and the aqueous solution of the assembly was added into the plate with the final concentration of $0.5 \mathrm{mg} / \mathrm{mL}$. The plate was then incubated in a humidified $5 \% \mathrm{CO}_{2}$ in air incubator at $37{ }^{\circ} \mathrm{C}$ for different times. The cells were washed with $100 \mu \mathrm{L}$ of phosphate buffer saline (PBS) three times. Finally, the total volume of $100 \mu \mathrm{L}$ was added into the plate. The cells were imaged by a confocal laser 
scanning microscope. All parameters of the microscope remained constant in the entire testing process. The fluorescence intensity of each cell was measured by CLSM. The mean fluorescence intensity was defined as the total fluorescence intensity divided by the total cell number. ${ }^{37,38}$

\section{RESULTS AND DISCUSSION}

The PNAG- $b$-PNOG diblock copolypeptoids were synthesized by sequential ring-opening polymerization of Oct-NCA using PNAG as the macroinitiator (Scheme 1). By varying the

Scheme 1. Synthetic Route to the Diblock Copolypeptoids

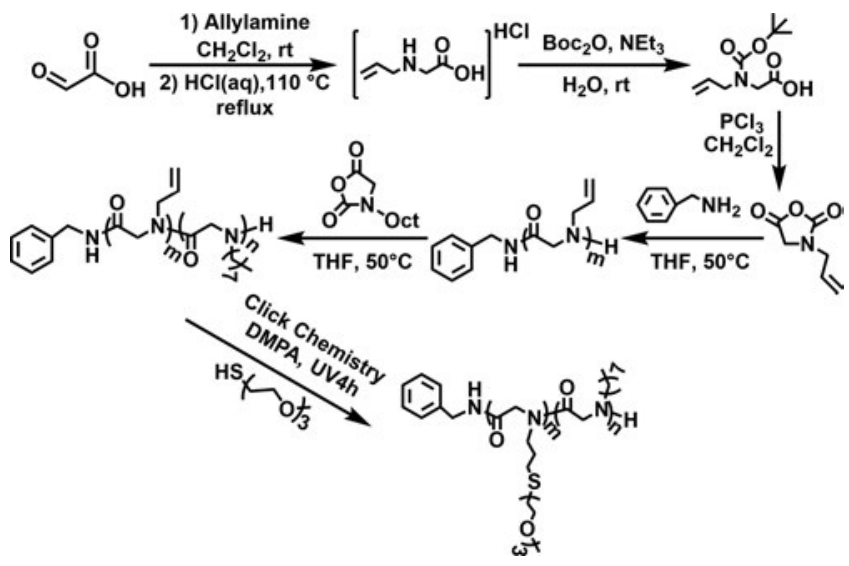

monomer/initiator ratio, a series of diblocks with different DPs were obtained. The chemical structures and DPs of the blocks were investigated by ${ }^{1} \mathrm{H}$ NMR spectroscopy (Figure 1a). All

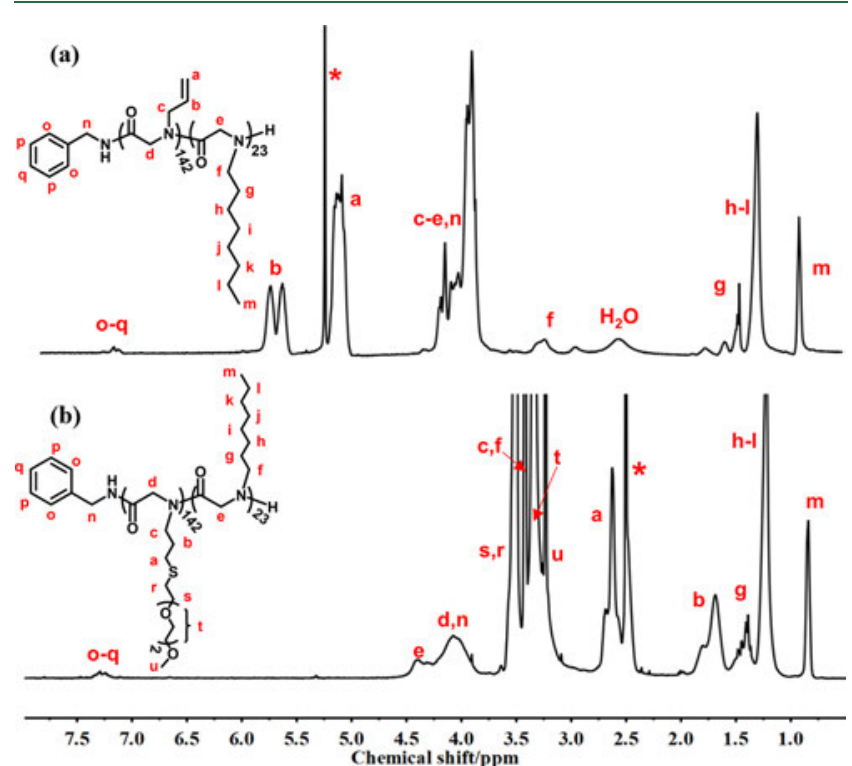

Figure 1. (a) ${ }^{1} \mathrm{H}$ NMR spectra of $\mathrm{PNAG}_{142}-b-\mathrm{PNOG}_{23}$ in $\mathrm{CD}_{2} \mathrm{Cl}_{2}$ (* indicates $\mathrm{CD}_{2} \mathrm{Cl}_{2}$ ). (b) ${ }^{1} \mathrm{H}$ NMR spectra of (PNAG-g-EG $\left.{ }_{3}\right)_{142}-b$ $\mathrm{PNOG}_{23}$ in DMSO- $d_{6}$ (* indicates DMSO- $\left.d_{6}\right)$. The molecular characteristics are shown in Table $S 1$.

peaks of the diblock copolymers are well assigned in the ${ }^{1} \mathrm{H}$ NMR spectra, confirming the diblock chemical structures. Table S1 summarizes the molar mass and dispersity $(\boxplus)$ of all of the samples, where the subscripts correspond to the DPs, respectively. The GPC traces show narrow weight distributions with $Ð \leq 1.24$. The polypeptoids were then conjugated with
$\mathrm{OEG}_{3}-\mathrm{SH}$ to yield (PNAG- $-\mathrm{EG}_{3}$ )- $b$-PNOG. In a typical ${ }^{1} \mathrm{H}$ NMR spectrum, the protons of the OEG moiety at $3.5 \mathrm{ppm}$ are visible, while the protons of the allyl group completely disappear, suggesting the quantitative conversion of the alkenyl group (Figure $1 \mathrm{~b}$ ). GPC traces of (PNAG- $g-\mathrm{EG}_{3}$ )- $b$-PNOG reveal a similar dispersity with a noticeable shift to a higher molar mass region, indicative of insignificant side reactions in the process of postmodification (Figure S1). The minor shoulder can be attributed to the byproducts during thiol-ene click chemistry, ${ }^{39}$ which is typically seen in previous reports. Similarly, a series of PNAG- $g-E_{3}$ with different DPs were obtained. The molecular characteristics of (PNAG- $g-E_{3}$ )- $b$ PNOG along with their abbreviations are shown in Table $S 1$.

The thermal properties of (PNAG- $g-E_{3}$ )- $b$-PNOG were first investigated by DSC measurements as shown in Figure S2 and summarized in Table S2. The $\mathrm{PNOG}_{20}$ homopolymer is crystallizable with two melting transitions at around 51 and $163{ }^{\circ} \mathrm{C}$ as reported, which are associated with different chain packings of both side chains and backbones. ${ }^{31}$ In marked contrast, the lack of melting peaks and crystallization exotherms suggests that the PNAG- $g-E_{3}$ segment is noncrystalline. With a high molar fraction of PNOG, the DSC endotherms of diblock copolymers display two peaks with similar melting transitions to PNOG homopolymers. As the molar fraction of PNOG is decreased to 0.27 or lower, merely one broad melting transition with centered peaks in the range of $53-61{ }^{\circ} \mathrm{C}$ is present, suggesting that crystallization of PNOG is largely suppressed by the presence of PNAG- $g-E_{3}$. This is further confirmed by the decreased melting enthalpy and melting temperature with increasing molar fraction of PNAG- $g-\mathrm{EG}_{3}$.

Pegylated poly $(N$-propargylglycine $)$ has been reported to show an LCST behavior in aqueous solution. ${ }^{36}$ These polymers can readily dissolve in water at room temperature and collapse at elevated temperatures. Further cooling can result in a reversible phase transition. As expected, PNAG- $g$ $\mathrm{EG}_{3}$ also exhibits a similar reversible LCST behavior, as shown in Figure S3. A representative plot of $\mathrm{PNAG}_{95}-g-\mathrm{EG}_{3}$ demonstrates a $\mathrm{CP}$ of around $49.4{ }^{\circ} \mathrm{C}$ with $50 \%$ transmittance during heating. The $\mathrm{CP}_{\text {cooling }}$ of $48.8{ }^{\circ} \mathrm{C}$ is shown with $100 \%$ recovered transmittance during the cooling ramp. This variation in CPs could be explained by the overcooling during rehydration of OEG units as reported. ${ }^{40}$ As the DP of the polymer decreases from 95 to 59 , the CP increases from 49.4 to $51.2{ }^{\circ} \mathrm{C}$. We attribute this to the increased solubility of shorter polymer chains that results in enhanced CPs. ${ }^{41}$ The incorporation of the PNOG block significantly decreases the $\mathrm{CPs}$ of the systems by $10-15{ }^{\circ} \mathrm{C}$, which is associated with the decreased solubility (Figure 2). Further, as compared to the homopolymer $\mathrm{PNAG}_{95}-\mathrm{g}-\mathrm{EG}_{3}$ that shows high dependence of $\mathrm{CP}$ on concentration, the $\mathrm{CP}$ of the block copolymer $\left(\mathrm{PNAG}_{94}-g-\mathrm{EG}_{3}\right)-b-\mathrm{PNOG}_{15}$ with almost the same DP of pegylated PNAG varies slightly with concentration change. We assume that this is because the formation of the aggregates reduces the intermolecular interaction at high concentrations. We will address this shortly. More interestingly, the CPs during the heating and cooling runs remain nearly the same, which indicates the rapid rehydration of OEG units. This is possibly because the OEG moieties are aggregated, which increases the hydrogen-bonding interaction with water. ${ }^{42}$ Furthermore, with a fixed DP of the PNOG block, increasing the DP of PNAG- $g$ $\mathrm{EG}_{3}$ reduces the $\mathrm{CP}$, consistent with the homopolypeptoids. In addition, increasing the DP of PNOG can also decrease the CP 


\section{Biomacromolecules}

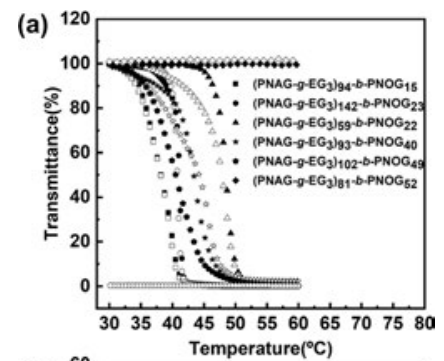

(b)

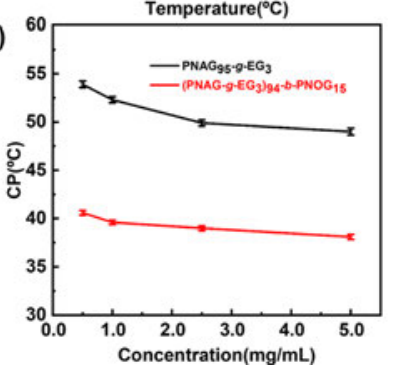

Figure 2. (a) Plots of transmittance versus temperature for aqueous solutions of (PNAG- $g-\mathrm{EG}_{3}$ ) $-b$-PNOG at a concentration of $5 \mathrm{mg} / \mathrm{mL}$. Filled symbol: heating ramp and open symbol: cooling ramp. (b) Plots of CP versus concentration for aqueous solutions of (PNAG- $g$ $\left.\mathrm{EG}_{3}\right)_{94^{-}}-\mathrm{PNOG}_{15}$ and $\mathrm{PNAG}_{95}-g-\mathrm{EG}_{3}$ at different concentrations.

with a fixed DP of PNAG- $g-E_{3}$ due to the increased hydrophobicity of PNOG. Note that as the DP of the PNOG increases to 49 and the molar fraction of PNOG is 0.32 , the sample shows an irreversible LCST behavior. Further increasing the DP of PNOG to 52 and the molar fraction to 0.39 results in the absence of the LCST property. In most cases, the phase transition of both the homopolymer and block copolymer is recovered after 8 heating and cooling cycles between 30 and $60^{\circ} \mathrm{C}$, suggesting good stability (Figure S4a). Further, the CPs remain constant with addition of salt. This suggests that both systems are stable to brine, which provides great potential for biomedical applications (Figure S4b).

All of the block copolymers can be readily dispersed in water at room temperature, possibly due to the significantly long chain length of the PNAG- $g-E_{3}$ block with good water solubility. Considering the amphiphilicity of the system, the copolymers are expected to form assemblies. We performed TEM characterization to determine the shape of nanostructures. Upon negative staining, TEM images of the (PNAG- $g$ $\left.\mathrm{EG}_{3}\right)_{142}-b-\mathrm{PNOG}_{23}$ copolymer with the lowest molar fraction of PNOG of 0.14 reveal the presence of a spherical-shapedstructure with an average diameter of $11.5 \mathrm{~nm}$ when prepared at room temperature after 1 day of stirring (Figure 3a). AFM characterization confirms the spherical structures with a similar diameter $(\sim 11.2 \mathrm{~nm})$ and comparable height $(\sim 4.1 \mathrm{~nm})$, consistent with TEM results (Figure $3 b$ ). It is conceivable that the hydrophilic PNAG- $g$ - $\mathrm{EG}_{3}$ forms the shell and the hydrophobic PNOG constitutes the core of the spheres, thus leading to the micellar core-shell structure. Similarly, the diblock copolymer (PNAG- $\left.g-E_{3}\right)_{94}-b-\mathrm{PNOG}_{15}$ with the same molar fraction of PNOG but a smaller molar mass shows a majority of sphere-like morphology with an average diameter of $9.8 \mathrm{~nm}$, as observed by TEM (Figure 3c). A few cylindrical aggregates with a diameter similar to that of the spheres are occasionally present. The presence of cylinders probably result from a fusion process of the spheres, as evidenced by AFM (Figure 3d). ${ }^{43,44}$ As the molar fraction of PNOG increases, the predominant morphology is observed to be cylindrical, pubs.acs.org/doi/10.1021/acs.biomac.0c00844
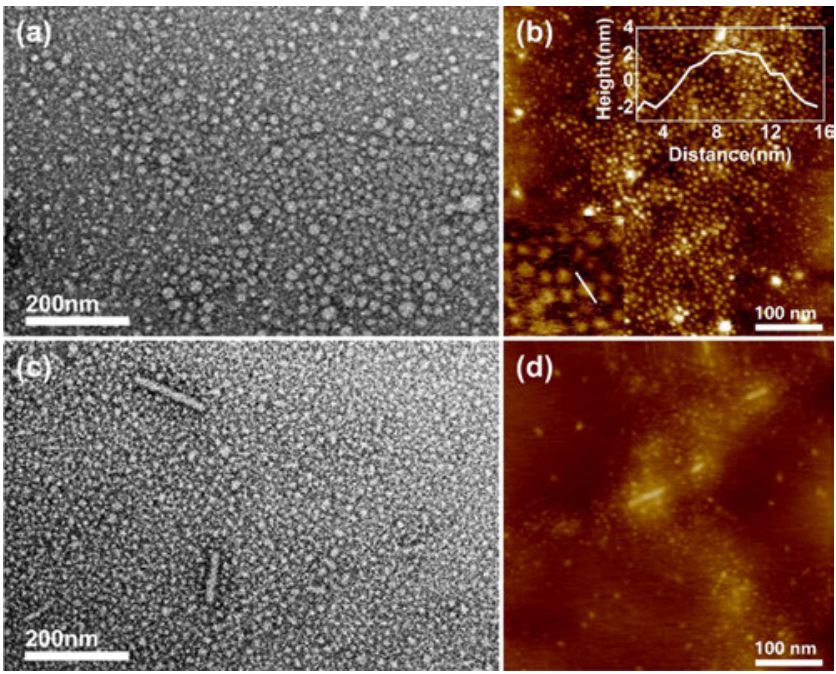

Figure 3. TEM images of (PNAG- $\left.g-E_{3}\right)_{142}-b-P_{N O G}$ (a) and (PNAG- $\left.g-E_{3}\right)_{94}-b-\mathrm{PNOG}_{15}$ (c) stirred for $24 \mathrm{~h}$ at room temperature in aqueous solution at a concentration of $1 \mathrm{mg} / \mathrm{mL}$. AFM images of $\left(\mathrm{PNAG}-g-\mathrm{EG}_{3}\right)_{142}-b-\mathrm{PNOG}_{23}$ (b) and (PNAG- $\left.g-\mathrm{EG}_{3}\right)_{94}-b-\mathrm{PNOG}_{15}$ (d) stirred for $24 \mathrm{~h}$ at room temperature in aqueous solution at a concentration of $1 \mathrm{mg} / \mathrm{mL}$.

irrespective of the molar mass of the block copolymer (Figure S5).

As expected, the self-assemblies exhibit a thermoresponsive behavior upon heating. With the (PNAG- $\left.g-\mathrm{EG}_{3}\right)_{142}-b-\mathrm{PNOG}_{23}$ solution heated up to $60{ }^{\circ} \mathrm{C}\left(>\mathrm{CP}\right.$ of $\left.\sim 41.1^{\circ} \mathrm{C}\right)$, a sphere-tocylinder transition is explicitly shown. Figure 4 a shows that the length of the cylinders is up to $\sim 560 \mathrm{~nm}$ and the diameter is $\sim 11.3 \mathrm{~nm}$, nearly identical to the diameter of the spheres. The PNAG- $g-E_{3}$ collapses with the temperature increasing above the $\mathrm{CP}$, which enables protruding sticky ends of PNOG to fuse with the adjacent one to grow into cylinders. Note that the amide bonds on the backbone of the copolymers can form hydrogen bonding with water, which stabilizes the system. It is known that polysarcosine with one methyl group on the side chain shows excellent solubility in water. ${ }^{27}$ A type of semi-bald micelle has been reported by both simulations and experiments for the thermogelling mechanism, which is likely to occur. ${ }^{45}$ In most previous reports, the assemblies from thermoresponsive diblock copolymers exhibit reversible morphological evolution with temperature. ${ }^{46-50}$ Remarkably, Figure $4 \mathrm{~b}$ shows that the cylindrical nanostructure persists with similar dimensions as the solution cools back to the room temperature. We assume that this irreversible transition is due to the presence of crystalline PNOG within the core that restricts the disassembly of the system. To probe the detailed molecular packing and assembly mechanism, grazing incidence wide-angle X-ray scattering (GIWAXS) was performed (Figure 5a). The scattering peak at the $q=q^{*}=3.0 \mathrm{~nm}^{-1}$ in plane is due to the Bragg reflections of PNOG crystals, associated with the side-chain packing as reported. ${ }^{30}$ The spacing is given by $d=$ $2 \pi / q=2.1 \mathrm{~nm}$. An additional broad peak at around $14.1 \mathrm{~nm}^{-1}$ indicates the disordered packing, confirming that the crystallization of PNOG is suppressed. It is shown that as the solution is heated to $60{ }^{\circ} \mathrm{C}$ additional higher-order peaks at $2 q^{*}$ and $3 q^{*}$ are visible, indicative of the presence of the lamellae. The variations suggest that the cylinders contain higher-ordered packing of PNOG domains (Scheme 2). Note that the (PNAG- $\left.g-\mathrm{EG}_{3}\right)_{142}-b-\mathrm{PNOG}_{23}$ bulk sample melts over 

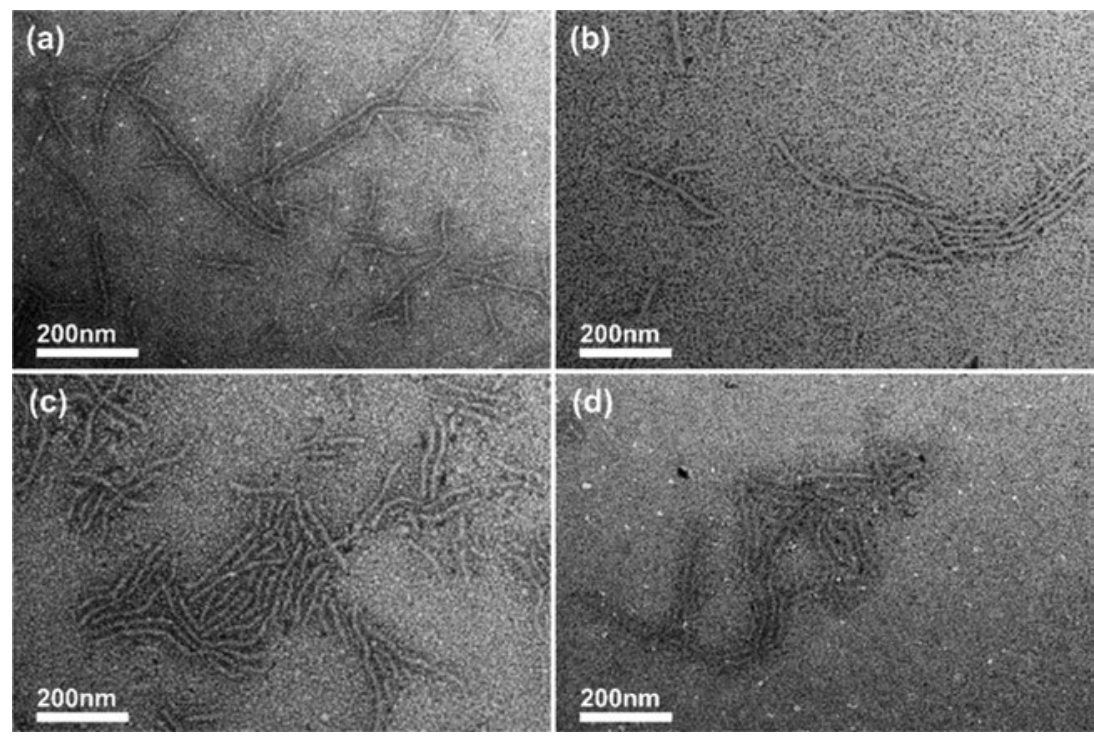

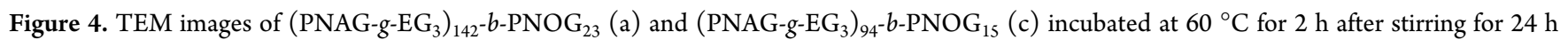
at room temperature in aqueous solution at a concentration of $1 \mathrm{mg} / \mathrm{mL}$ (grid prepared at $60{ }^{\circ} \mathrm{C}$ ). TEM images of $\left(\mathrm{PNAG}-\mathrm{g}-\mathrm{EG}_{3}\right)_{142}-b-\mathrm{PNOG}_{23}$ (b) and (PNAG- $\left.g-\mathrm{EG}_{3}\right)_{94}-b-\mathrm{PNOG}_{15}(\mathrm{~d})$ after cooling the solutions in (a) and (c) to the room temperature, respectively.
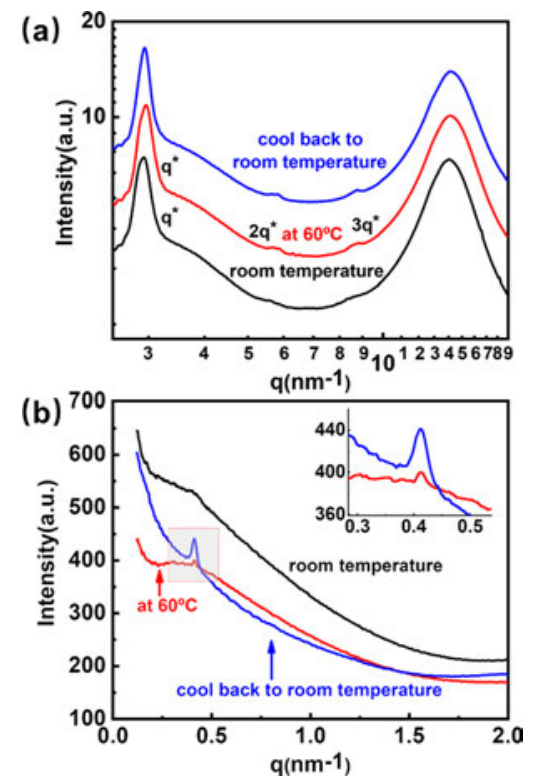

Figure 5. GIWAXS in-plane (a) and SAXS (b) measurements of the sphere and cylinder from (PNAG- $\left.g-\mathrm{EG}_{3}\right)_{142}-b-\mathrm{PNOG}_{23}$ in aqueous solution at a concentration of $1 \mathrm{mg} / \mathrm{mL}$. The black line represents the (PNAG- $\left.g-\mathrm{EG}_{3}\right)_{142}-b-\mathrm{PNOG}_{23}$ stirred for $24 \mathrm{~h}$ at room temperature in aqueous solution at a concentration of $1 \mathrm{mg} / \mathrm{mL}$. The red line represents the (PNAG-g-EG $)_{142}-b-\mathrm{PNOG}_{23}$ incubated at $60{ }^{\circ} \mathrm{C}$ for 1 $\mathrm{h}$ after stirring for $24 \mathrm{~h}$ at room temperature in aqueous solution at a concentration of $1 \mathrm{mg} / \mathrm{mL}$. The blue line represents the (PNAG-g$\left.\mathrm{EG}_{3}\right)_{142}-b-\mathrm{PNOG}_{23}$ cooled to the room temperature after stirring for $24 \mathrm{~h}$ at room temperature and incubating at $60{ }^{\circ} \mathrm{C}$ for $1 \mathrm{~h}$ in aqueous solution at a concentration of $1 \mathrm{mg} / \mathrm{mL}$.

a wide range of $\sim 40-70{ }^{\circ} \mathrm{C}$. Thus, the PNOG may partially melt and the increased mobility enables the long-range order of polymer chains for the thermodynamically favorable transition. As the solution cools to room temperature, a sharpened primary peak and higher-order peaks suggest more ordered chain packing. It is thus conceivable that the restrained PNOG chains prevent the reversible morphological evolution from
Scheme 2. Sphere and Cylinder Structure of the Crystalline Diblock Copolypeptoids

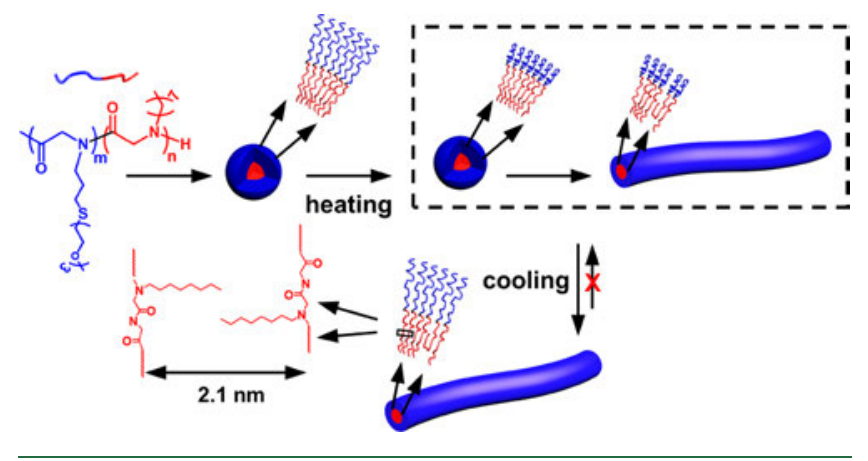

cylinders to spheres. We therefore propose that the LCST behavior of the system initiates the assembly process by enabling collapsed PNAG- $g$-EG $E_{3}$ chains and exposure of PNOG sites with the temperature increasing above the CP. Subsequent crystallization of PNOG promotes the formation of the cylinder and further stabilizes the architecture with confined crystalline domains. Note that despite the thermoresponsive behavior being recovered after 8 times of heating and cooling runs, the cylindrical assembly is significantly stable after the first cooling process (Figure S4a). This suggests that the "locked" morphology is independent of the environmental conditions once formed.

Aqueous solution of the assemblies was further analyzed by SAXS. A clear Bragg-like scattering peak at $0.41 \mathrm{~nm}^{-1}$ in a low$q$ range is observed in the heating and recooling solution (Figure $5 \mathrm{~b}$ ). Note that the peak intensity in the recooling process is more pronounced than that in the heating process. The spacing is ca. $15.2 \mathrm{~nm}$, which can be attributed to the repeating units of a cluster of laterally arrayed filaments, consistent with the TEM images in the dry state. We have previously observed that the fibers assembled from poly(ethylene glycol)-b-poly( $N$-(2-phenylethyl)glycine) align laterally in water and further fuse into platelets. ${ }^{51}$ In this case, the absence of nanosheets is perhaps due to the long hydrophilic 

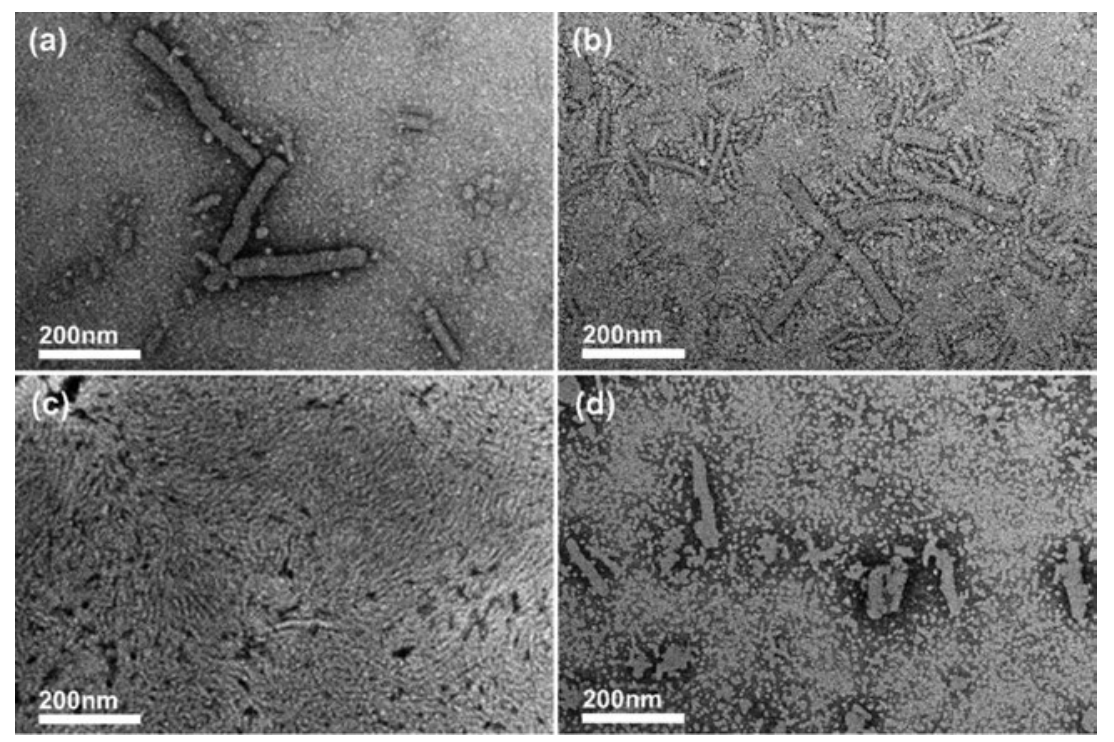

Figure 6. TEM images of (PNAG-g-EG $)_{102}-b-\mathrm{PNOG}_{49}$ (a) and (PNAG- $\left.g-\mathrm{EG}_{3}\right)_{81}-b-\mathrm{PNOG}_{52}$ (c) incubated at $60{ }^{\circ} \mathrm{C}$ for $2 \mathrm{~h}$ after stirring for $24 \mathrm{~h}$ at room temperature in aqueous solution at a concentration of $1 \mathrm{mg} / \mathrm{mL}$ (grid prepared at $60{ }^{\circ} \mathrm{C}$ ). TEM images of $\left(\mathrm{PNAG}-\mathrm{g}-\mathrm{EG}_{3}\right)_{102}-b-\mathrm{PNOG}_{49}$ (b) and (PNAG- $\left.g-E_{3}\right)_{81}-b-$ PNOG $_{52}$ (d) after cooling the solutions in (a) and (c) to the room temperature, respectively.

PNAG- $g$-EG $\mathrm{EG}_{3}$ segments that prevent the lateral cohesion of the fibers. Note that the diameter from TEM is smaller than that from SAXS, which is possibly because of the volume shrinkage of the assemblies during the drying process and an invisible corona with a low electron density by TEM. ${ }^{52}$ This result confirms that the fibers assemble at an elevated temperature in aqueous solution and remain stable upon recooling, which agrees well with the proposed mechanisms.

Note that simply increasing the stirring time to 5 days and the concentration to $5 \mathrm{mg} / \mathrm{mL}$ at room temperature results in exclusively spheres (Figure S6). Increasing the incubation time at elevated temperatures results in consistent morphologies as well (Figure S7). We thus assume that the temperature is significantly crucial for the cylinder formation. To further study the detailed assembly kinetics, we performed the experiments at various temperatures (Figure S8). As expected, it is shown that merely spheres are visible as the (PNAG- $\left.g-E_{3}\right)_{142}-b$ $\mathrm{PNOG}_{23}$ is heated to $40{ }^{\circ} \mathrm{C}$, slightly lower than the $\mathrm{CP}$. Heating the sample up to $50{ }^{\circ} \mathrm{C}(>\mathrm{CP})$ results in the coexistence of the spheres and cylinders with a similar diameter of $\sim 11.3 \mathrm{~nm}$. Since the (PNAG- $\left.g-\mathrm{EG}_{3}\right)_{142}-b-\mathrm{PNOG}_{23}$ bulk sample melts over a wide range centered at around $60{ }^{\circ} \mathrm{C}$, it is likely that the mobility of PNOG is insufficient to organize into dense-packed crystals at $50{ }^{\circ} \mathrm{C}$, which leads to the reversible transition to spheres at room temperature. Further increasing the temperature up to $80^{\circ} \mathrm{C}$ results in the formation of cylindrical structures. However, the length of the cylinders $(\sim 150 \mathrm{~nm})$ is typically shorter than that prepared at $60^{\circ} \mathrm{C}$. We assume that this is possibly because the PNOG completely melts at $80{ }^{\circ} \mathrm{C}$, and the assemblies are mainly driven by hydrophobicity and the lack of order. Further cooling down to below the $\mathrm{CP}$ results in formation of a long hairy shell that disfavors the long-range ordered packing.

Similarly, Figure 4c,d shows that (PNAG-g-EG $)_{94}-b$ PNOG $_{15}$ with the same molar fraction of PNOG exhibit an irreversible sphere-to-cylinder transition. As the molar fraction of PNOG is increased to 0.27 and 0.30 , both (PNAG- $g$ $\left.\mathrm{EG}_{3}\right)_{59}-b-\mathrm{PNOG}_{22}$ and $\left(\mathrm{PNAG}-g-\mathrm{EG}_{3}\right)_{93}-b-\mathrm{PNOG}_{40}$ remain as the cylindrical structures during the heating-cooling cycle despite the different molar masses (Figure S9). In both cases, the lengths of cylinders significantly grow from $\sim 143$ to 386 $\mathrm{nm}$ and $\sim 156$ to $403 \mathrm{~nm}$ upon heating, respectively. Both lengths persist after cooling back to the room temperature. This short-to-long cylinder transition is very consistent with the sphere-to-cylinder transition. Further increasing the molar fraction of PNOG results in the formation of a twodimensional nanosheet of (PNAG- $\left.g-E_{3}\right)_{102}-b-\mathrm{PNOG}_{49}$ and $\left(\mathrm{PNAG}-g-\mathrm{EG}_{3}\right)_{81}-b-\mathrm{PNOG}_{52}$, as shown in Figure 6. In both cases, two melting transitions are observed by DSC. The AFM images show sheetlike structures with thicknesses of $\sim 4.2$ and $4.5 \mathrm{~nm}$, respectively, which are comparable to the spheres (Figure S10). Interestingly, it is observed that both samples behave fairly distinctly at elevated temperatures. In the case of (PNAG- $\left.g-\mathrm{EG}_{3}\right)_{102}-b-\mathrm{PNOG}_{49}$, the nanosheet forms upon heating and remains during the cooling process. As the temperature increases to the first melting transition temperature, the PNAG- $g-E_{3}$ chains collapse and simultaneously PNOG chains transition into a mesophase, both of which enable the higher-ordered structures. However, (PNAG- $g$ $\left.\mathrm{EG}_{3}\right)_{81}$ - $b$-PNOG 52 assembles into nanosheets merely after the solution is cooled back to room temperature. The cylinders are exclusively observed at elevated temperatures, which suggests that the assembly of nanosheets is initiated upon cooling. Note that (PNAG- $\left.g-\mathrm{EG}_{3}\right)_{81}-b-\mathrm{PNOG}_{52}$ excludes the thermoresponsive property over the entire experimental range. Although largely the chain mobility increases in the mesophase, the formation of nanosheets is inhibited by the long hairy PNAG$g-\mathrm{EG}_{3}$ block during heating (Scheme 3 ). In this specific case, the formation of nanosheets is entirely driven by crystallization of PNOG upon cooling. This confirms the proposed formation mechanism, where the collapsed PNAG- $g-E_{3}$ chains first facilitate the packing of exposed PNOG, followed by promotion of crystallization. Note that the nanosheets assembled from (PNAG- $\left.g-E_{3}\right)_{81}-b-\mathrm{PNOG}_{52}$ appear to be more irregular than those from (PNAG- $\left.g-\mathrm{EG}_{3}\right)_{102}-b-\mathrm{PNOG}_{49}$. This suggests that well-controlled structures can be obtained by incorporating hydrophilic segments with the thermores- 


\section{Biomacromolecules}

Scheme 3. Cylinder and Nanosheet Structure of the Crystalline Diblock Copolypeptoids

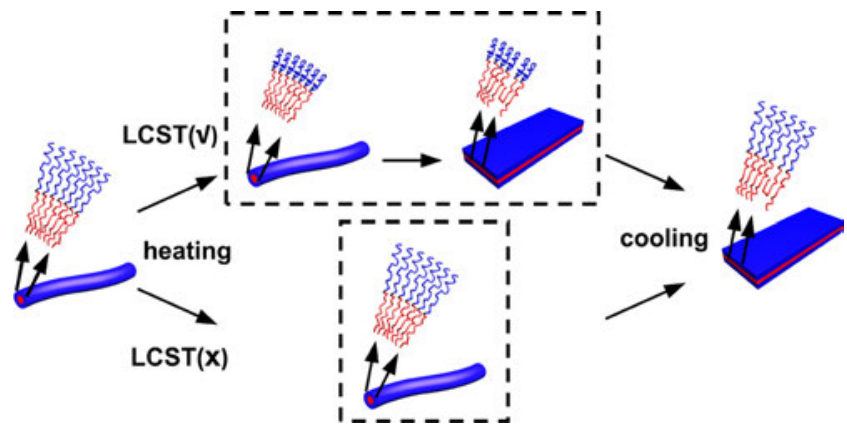

ponsive property, which offers great potential for biomedical applications.

In nature, a number of viruses that infect animals exhibit a cylindrical morphology, indicative of possible morphological advantages. ${ }^{53-55}$ Compared to a large number of studies of size and surface chemistry effects on cellular uptake behaviors, merely a few studies have been conducted on the influence of morphology. ${ }^{15,17,56-59}$ In this study, we addressed this issue by comparing cellular uptakes of spherical and cylindrical structures in three types of cells by CLSM. The diblock copolymer (PNAG- $\left.g-E_{3}\right)_{142}-b-\mathrm{PNOG}_{23}$ was first labeled with FITC quantitatively (Figure S11). The cellular uptakes were assessed in HeLa cells for potential application in tumor therapy. The CLSM images of HeLa cells after incubation with both FITC-labeled assemblies for $2 \mathrm{~h}$ clearly show that both assemblies are internalized by the cells (Figure 7). Further, the

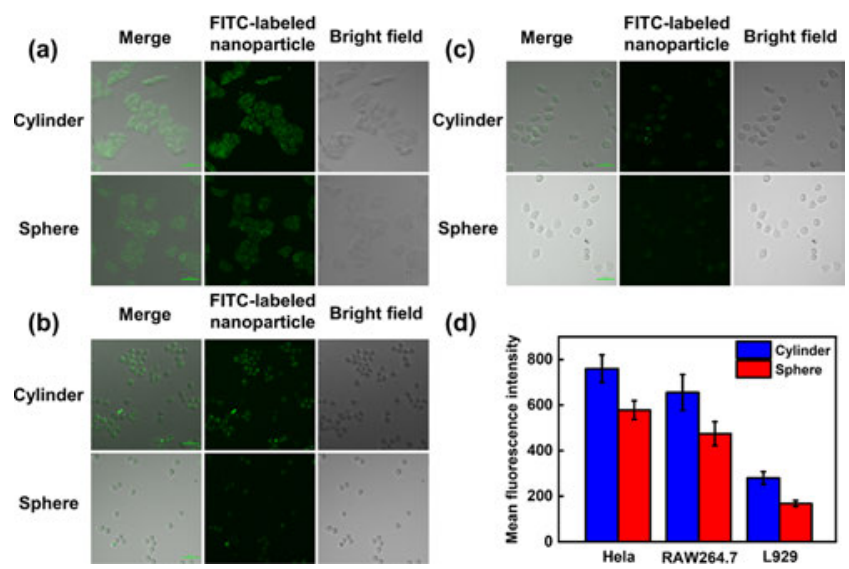

Figure 7. Confocal laser scanning microscopy images of HeLa cells after $2 \mathrm{~h}$ incubation (a), RAW264.7 after $2 \mathrm{~h}$ incubation (b), and L929 cells after $4 \mathrm{~h}$ incubation (c) with FITC-labeled assemblies at a concentration of $0.5 \mathrm{mg} / \mathrm{ml}$ at $37^{\circ} \mathrm{C}$. Scale bars $=50 \mu \mathrm{m}$. (d) Mean fluorescence intensity in HeLa cells, RAW264.7, and L929 cells after 2 $\mathrm{h}$ incubation with FITC-labeled nanoparticle assemblies at a concentration of $0.5 \mathrm{mg} / \mathrm{ml}$ at $37^{\circ} \mathrm{C}$.

fluorescence intensity from the cylindrical assembly is significantly higher than that from the spheres, quantitatively confirmed by mean fluorescence intensity determination (Figure 7d). The time-dependent experiment further shows that the copolymers formulated in cylindrical assemblies are initially internalized to a higher extent than those in spherical ones, and eventually reach a comparable value (Figure S12). Note that nearly all of the cells spread very well after $16 \mathrm{~h}$, indicating the low cytotoxicity of the biocompatible poly- pubs.acs.org/doi/10.1021/acs.biomac.0c00844

peptoids as previously reported. ${ }^{60}$ Similar morphology-dependent cellular uptake behaviors were also observed in RAW264.7 and L929 cells by CLSM. In L929 cells, the fluorescence intensity is lower than that in the other two cells, indicating the lower cellular uptake. Note that the cylinders are much larger in volume compared with the spheres. Thus, it is hypothesized that the long and flexible structure may span across a larger contact area for stronger and faster binding with cell membranes. ${ }^{56,58}$

\section{CONCLUSIONS}

In summary, we have designed and synthesized a series of diblock copolypeptoids (PNAG- $g$-EG 3 )- $b$-PNOG that exhibit a reversible thermoresponsive behavior with nearly the same CPs during the heating and cooling runs in aqueous solution. Remarkably, the morphology transition of the assemblies observed upon heating becomes irreversible upon cooling because of the presence of crystalline PNOG. This PNOG behaves as a chemical leverage to "freeze" cylindrical morphologies obtained above the $\mathrm{CP}$ at temperatures below the same CP. We have therefore demonstrated a CDSA process combined with nanoprecipitation initiated by thermostimulus. Specifically, the thermoresponsive property of the system initiates the assembly process, promoted by subsequent crystallization of PNOG and physically locks the morphology eventually. Both thermoresponsive and crystalline features coordinately facilitate the architecture and assembly kinetics. Such a process allows the formation of different nanostructured assemblies from the same block copolymers. We have further studied the influence of nanoparticles' shape on cell internalization while keeping all molecular parameters constant. Cellular uptake experiments using three types of cells have shown that the copolymers formulated in cylindrical assemblies are initially internalized to a greater extent than those in spherical ones of identical surface chemistry and eventually reach a comparable value. This combined selfassembly strategy offers a new opportunity to construct new generations of bioinspired nanomaterials with bioactive hierarchical nanostructures for biomedical applications.

\section{ASSOCIATED CONTENT}

\section{Supporting Information}

The Supporting Information is available free of charge at https://pubs.acs.org/doi/10.1021/acs.biomac.0c00844.

Additional GPC data, DSC data, NMR data, GIWAXS results, TEM images, and AFM images (PDF)

\section{AUTHOR INFORMATION}

\section{Corresponding Authors}

Sébastien Lecommandoux - Univ. Bordeaux, CNRS,

Bordeaux INP, LCPO, F-33600 Pessac, France;

Email: lecommandoux@enscbp.fr

Zhibo Li - Key Laboratory of Biobased Polymer Materials, College of Polymer Science and Engineering, Qingdao University of Science and Technology, Qingdao 266042, China; Email: zbli@qust.edu.cn

Jing Sun - Key Laboratory of Biobased Polymer Materials, College of Polymer Science and Engineering, Qingdao University of Science and Technology, Qingdao 266042, China; 가이.org/0000-0003-1267-0215; Email: jingsun@ qust.edu.cn 


\section{Biomacromolecules}

\section{Authors}

Zhiwei Wang - Key Laboratory of Biobased Polymer Materials, College of Polymer Science and Engineering, Qingdao University of Science and Technology, Qingdao 266042, China

Min Lin - Key Laboratory of Biobased Polymer Materials, College of Polymer Science and Engineering, Qingdao University of Science and Technology, Qingdao 266042, China

Colin Bonduelle - Univ. Bordeaux, CNRS, Bordeaux INP, LCPO, F-33600 Pessac, France; (1) orcid.org/0000-00027213-7861

Rongye Li - Key Laboratory of Biobased Polymer Materials, College of Polymer Science and Engineering, Qingdao University of Science and Technology, Qingdao 266042, China

Zhekun Shi - Key Laboratory of Biobased Polymer Materials, College of Polymer Science and Engineering, Qingdao University of Science and Technology, Qingdao 266042, China

Chenhui Zhu - Advanced Light Source, Lawrence Berkeley National Laboratory, Berkeley, California 94720, United States

Complete contact information is available at:

https://pubs.acs.org/10.1021/acs.biomac.0c00844

\section{Author Contributions}

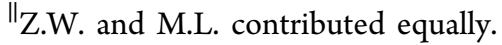

\section{Funding}

The National Natural Science Foundation of China (51722302 and 21674054), the Natural Science Foundation of Shandong Province (No. ZR2019JQ17), and the Taishan Scholars Program.

\section{Notes}

The authors declare no competing financial interest.

\section{ACKNOWLEDGMENTS}

BeamLine 7.3.3 at the Advanced Light Source is supported by the Director of the Office of Science, Office of Basic Energy Sciences of the U.S. Department of Energy under Contract No. DE-AC02-05CH11231. Ahmed Bentaleb from CRPP (UMR CNRS 5031) is acknowledged for his technical support with the SAXS experiments.

\section{REFERENCES}

(1) Whitesides, G. M.; Mathias, J. P.; Seto, C. T. Molecular selfassembly and nanochemistry: a chemical strategy for the synthesis of nanostructures. Science 1991, 254, 1312-1319.

(2) Zhang, S. Fabrication of novel biomaterials through molecular self-assembly. Nat. Biotechnol. 2003, 21, 1171-1178.

(3) Fratzl, P.; Weinkamer, R. Nature's hierarchical materials. Prog. Mater. Sci. 2007, 52, 1263-1334.

(4) Priemel, T.; Degtyar, E.; Dean, M. N.; Harrington, M. J. Rapid self-assembly of complex biomolecular architectures during mussel byssus biofabrication. Nat. Commun. 2017, 8, No. 14539.

(5) Kronqvist, N.; Otikovs, M.; Chmyrov, V.; Chen, G.; Andersson, M.; Nordling, K.; Landreh, M.; Sarr, M.; Jörnvall, H.; Wennmalm, S. Sequential $\mathrm{pH}$-driven dimerization and stabilization of the $\mathrm{N}$-terminal domain enables rapid spider silk formation. Nat. Commun. 2014, 5, No. 3254.

(6) Patra, S. K.; Ahmed, R.; Whittell, G. R.; Lunn, D. J.; Dunphy, E. L.; Winnik, M. A.; Manners, I. Cylindrical micelles of controlled length with a $\pi$-conjugated polythiophene core via crystallizationdriven self-assembly. J. Am. Chem. Soc. 2011, 133, 8842-8845.

(7) Qian, J.; Li, X.; Lunn, D. J.; Gwyther, J.; Hudson, Z. M.; Kynaston, E.; Rupar, P. A.; Winnik, M. A.; Manners, I. Uniform, high aspect ratio fiber-like micelles and block co-micelles with a crystalline $\pi$-conjugated polythiophene core by self-seeding. J. Am. Chem. Soc. 2014, 136, 4121-4124. pubs.acs.org/doi/10.1021/acs.biomac.0c00844

(8) Qian, J.; Guerin, G.; Lu, Y.; Cambridge, G.; Manners, I.; Winnik, M. A. Self-Seeding in One Dimension: An Approach To Control the Length of Fiberlike Polyisoprene-Polyferrocenylsilane Block Copolymer Micelles. Angew. Chem., Int. Ed. 2011, 50, 1622-1625.

(9) Schmelz, J.; Schedl, A. E.; Steinlein, C.; Manners, I.; Schmalz, H. Length control and block-type architectures in worm-like micelles with polyethylene cores. J. Am. Chem. Soc. 2012, 134, 14217-14225.

(10) Wang, X.; Guerin, G.; Wang, H.; Wang, Y.; Manners, I.; Winnik, M. A. Cylindrical block copolymer micelles and co-micelles of controlled length and architecture. Science 2007, 317, 644-647.

(11) Tao, D.; Feng, C.; Cui, Y.; Yang, X.; Manners, I.; Winnik, M. A.; Huang, X. Monodisperse fiber-like micelles of controlled length and composition with an oligo (p-phenylenevinylene) core via "living" crystallization-driven self-assembly. J. Am. Chem. Soc 2017, 139, 7136-7139.

(12) Fan, B.; Liu, L.; Li, J.-H.; Ke, X.-X.; Xu, J.-T.; Du, B.-Y.; Fan, Z.$\mathrm{Q}$. Crystallization-driven one-dimensional self-assembly of polyethylene-b-poly (tert-butylacrylate) diblock copolymers in DMF: effects of crystallization temperature and the corona-forming block. Soft Matter 2016, 12, 67-76.

(13) He, Y.; Eloi, J.-C.; Harniman, R. L.; Richardson, R. M.; Whittell, G. R.; Mathers, R. T.; Dove, A. P.; O’Reilly, R. K.; Manners, I. Uniform Biodegradable Fiber-Like Micelles and Block Comicelles via "Living" Crystallization-Driven Self-Assembly of Poly (1-lactide) Block Copolymers: The Importance of Reducing Unimer SelfNucleation via Hydrogen Bond Disruption. J. Am. Chem. Soc. 2019, 141, 19088-19098.

(14) Sun, L.; Petzetakis, N.; Pitto-Barry, A.; Schiller, T. L.; Kirby, N.; Keddie, D. J.; Boyd, B. J.; O’Reilly, R. K.; Dove, A. P. Tuning the size of cylindrical micelles from poly (L-lactide)-b-poly (acrylic acid) diblock copolymers based on crystallization-driven self-assembly. Macromolecules 2013, 46, 9074-9082.

(15) Li, Z.; Zhang, Y.; Wu, L.; Yu, W.; Wilks, T. R.; Dove, A. P.; Ding, H.-m.; O’Reilly, R. K.; Chen, G.; Jiang, M. Glyco-Platelets with Controlled Morphologies via Crystallization-Driven Self-Assembly and Their Shape-Dependent Interplay with Macrophages. ACS Macro Lett. 2019, 8, 596-602.

(16) Demirel, A. L.; Meyer, M.; Schlaad, H. Formation of Polyamide Nanofibers by Directional Crystallization in Aqueous Solution. Angew. Chem., Int. Ed. 2007, 46, 8622-8624.

(17) Petzetakis, N.; Dove, A. P.; O’Reilly, R. K. Cylindrical micelles from the living crystallization-driven self-assembly of poly (lactide)containing block copolymers. Chem. Sci. 2011, 2, 955-960.

(18) Song, Y.; Chen, Y.; Su, L.; Li, R.; Letteri, R. A.; Wooley, K. L. Crystallization-driven assembly of fully degradable, natural productbased poly(1-lactide)-block-poly ( $\alpha$-d-glucose carbonate)s in aqueous solution. Polymer 2017, 122, 270-279.

(19) Legros, C.; De Pauw-Gillet, M.-C.; Tam, K. C.; Taton, D.; Lecommandoux, S. Crystallisation-driven self-assembly of poly (2isopropyl-2-oxazoline)-block-poly (2-methyl-2-oxazoline) above the LCST. Soft Matter 2015, 11, 3354-3359.

(20) Gelain, F.; Silva, D.; Caprini, A.; Taraballi, F.; Natalello, A.; Villa, O.; Nam, K. T.; Zuckermann, R. N.; Doglia, S. M.; Vescovi, A. BMHP1-derived self-assembling peptides: hierarchically assembled structures with self-healing propensity and potential for tissue engineering applications. ACS. Nano 2011, 5, 1845-1859.

(21) Yuan, C.; Ji, W.; Xing, R.; Li, J.; Gazit, E.; Yan, X. Hierarchically oriented organization in supramolecular peptide crystals. Nat. Rev. Chem. 2019, 3, 567-588.

(22) O’leary, L. E.; Fallas, J. A.; Bakota, E. L.; Kang, M. K.; Hartgerink, J. D. Multi-hierarchical self-assembly of a collagen mimetic peptide from triple helix to nanofibre and hydrogel. Nat. Chem. 2011, 3, 821.

(23) Kirshenbaum, K.; Zuckermann, R. N.; Dill, K. A. Designing polymers that mimic biomolecules. Curr. Opin. Struct. Biol. 1999, 9, 530-535.

(24) Zuckermann, R. N. Peptoid origins. Biopolymers 2011, 96, $545-55$. 
(25) Gangloff, N.; Ulbricht, J.; Lorson, T.; Schlaad, H.; Luxenhofer, R. Luxenhofer, Peptoids and polypeptoids at the frontier of supra-and macromolecular engineering. Chem. Rev. 2016, 116, 1753-1802.

(26) Zuckermann, R. N.; Kodadek, T. Peptoids as Potential Therapeutics. Curr. Opin. Mol. Ther. 2009, 11, 299-307.

(27) Birke, A.; Ling, J.; Barz, M. Polysarcosine-containing copolymers: Synthesis, characterization, self-assembly, and applications. Prog. Polym. Sci. 2018, 81, 163-208.

(28) Rosales, A. M.; Murnen, H. K.; Zuckermann, R. N.; Segalman, R. A. Control of Crystallization and Melting Behavior in Sequence Specific Polypeptoids. Macromolecules 2010, 43, 5627-5636.

(29) Lee, C.-U.; Li, A.; Ghale, K.; Zhang, D. Crystallization and Melting Behaviors of Cyclic and Linear Polypeptoids with Alkyl Side Chains. Macromolecules 2013, 46, 8213-8223.

(30) Shi, Z.; Wei, Y.; Zhu, C.; Sun, J.; Li, Z. Crystallization-Driven two-dimensional nanosheet from hierarchical self-assembly of polypeptoid-based diblock copolymers. Macromolecules 2018, 51, 6344-6351.

(31) Greer, D. R.; Stolberg, M. A.; Xuan, S.; Jiang, X.; Balsara, N. P.; Zuckermann, R. N. Liquid-Crystalline Phase Behavior in Polypeptoid Diblock Copolymers. Macromolecules 2018, 51, 9519-9525.

(32) Fetsch, C.; Luxenhofer, R. Thermal properties of aliphatic polypeptoids. Polymers 2013, 5, 112-127.

(33) Secker, C.; Völkel, A.; Tiersch, B.; Koetz, J.; Schlaad, H. Thermo-Induced Aggregation and Crystallization of Block Copolypeptoids in Water. Macromolecules 2016, 49, 979-985.

(34) Nazemi, A.; Boott, C. E.; Lunn, D. J.; Gwyther, J.; Hayward, D. W.; Richardson, R. M.; Winnik, M. A.; Manners, I. Monodisperse cylindrical micelles and block comicelles of controlled length in aqueous media. J. Am. Chem. Soc. 2016, 138, 4484-4493.

(35) Ni, Y.; Sun, J.; Wei, Y.; Fu, X.; Zhu, C.; Li, Z. Two-Dimensional Supramolecular Assemblies from pH-Responsive Poly(ethyl glycol)-bpoly(l-glutamic acid)-b-poly(N-octylglycine) Triblock Copolymer. Biomacromolecules 2017, 18, 3367-3374.

(36) Tian, J.; Sun, J.; Li, Z. Biomimetic pegylated polypeptoids with thermoresponsive properties. Polymer 2018, 138, 132-138.

(37) Polzer, H.; Haasters, F.; Prall, W. C.; Saller, M. M.; Volkmer, E.; Drosse, I.; Mutschler, W.; Schieker, M. Quantification of fluorescence intensity of labeled human mesenchymal stem cells and cell counting of unlabeled cells in phase-contrast imaging: an open-source-based algorithm. Tissue Eng., Part C 2010, 16, 12771285.

(38) Schenkel, M.; Sinclair, A. M.; Johnstone, D.; Bewley, J.; Mathur, $\mathrm{J}$. Visualizing the actin cytoskeleton in living plant cells using a photoconvertible mEos: FABD-mTn fluorescent fusion protein. Plant Methods 2008, 4, 21.

(39) Hoyle, C. E.; Bowman, C. N. Thiol-ene click chemistry. Angew. Chem., Int. Ed. 2010, 49, 1540-1573.

(40) Fu, X.; Tian, J.; Li, Z.; Sun, J.; Li, Z. Dual-responsive pegylated polypeptoids with tunable cloud point temperatures. Biopolymers 2019, 110, e23243.

(41) Tao, X.; Deng, Y.; Shen, Z.; Ling, J. Controlled polymerization of $\mathrm{N}$-substituted glycine $\mathrm{N}$-thiocarboxyanhydrides initiated by rare earth borohydrides toward hydrophilic and hydrophobic polypeptoids. Macromolecules 2014, 47, 6173-6180.

(42) Stals, P. J.; Haveman, J. F.; Martín-Rapún, R.; Fitié, C. F.; Palmans, A. R.; Meijer, E. The influence of oligo (ethylene glycol) side chains on the self-assembly of benzene-1, 3, 5-tricarboxamides in the solid state and in solution. J. Mater. Chem. 2009, 19, 124-130.

(43) Ouarti, N.; Viville, P.; Lazzaroni, R.; Minatti, E.; Schappacher, M.; Deffieux, A.; Borsali, R. Control of the morphology of linear and cyclic PS-b-PI block copolymer micelles via PS addition. Langmuir 2005, 21, 1180-1186.

(44) Burke, S. E.; Eisenberg, A. Kinetics and mechanisms of the sphere-to-rod and rod-to-sphere transitions in the ternary system PS310-b-PAA52/dioxane/water. Langmuir 2001, 17, 6705-6714.

(45) Cui, S.; Yu, L.; Ding, J. Semi-bald micelles and corresponding percolated micelle networks of thermogels. Macromolecules 2018, 51, $6405-6420$.
(46) Wang, Z.; Jiang, W. Temperature-induced reversible transformation between toroidal and cylindrical assemblies under shear flow. Soft Matter 2010, 6, 3743-3746.

(47) Du, Z. X.; Xu, J. T.; Fan, Z. Q. Regulation of Micellar Morphology of PCL-b-PEO Block Copolymers by Crystallization Temperature. Macromol. Rapid Commun. 2008, 29, 467-471.

(48) Wang, X.; Zhou, J.; Lv, X.; Zhang, B.; An, Z. Temperatureinduced morphological transitions of poly (dimethylacrylamide)poly (diacetone acrylamide) block copolymer lamellae synthesized via aqueous polymerization-induced self-assembly. Macromolecules 2017, 50, 7222-7232.

(49) McKenzie, B. E.; Nudelman, F.; Bomans, P. H.; Holder, S. J.; Sommerdijk, N. A. Temperature-responsive nanospheres with bicontinuous internal structures from a semicrystalline amphiphilic block copolymer. J. Am. Chem. Soc. 2010, 132, 10256-10259.

(50) Bhargava, P.; Tu, Y.; Zheng, J. X.; Xiong, H.; Quirk, R. P.; Cheng, S. Z. Temperature-induced reversible morphological changes of polystyrene-block-poly (ethylene oxide) micelles in solution. J. Am. Chem. Soc. 2007, 129, 1113-1121.

(51) Wei, Y.; Tian, J.; Zhang, Z.; Zhu, C.; Sun, J.; Li, Z. Supramolecular nanosheets assembled from poly (ethylene glycol)b-poly (N-(2-phenylethyl) glycine) diblock copolymer containing crystallizable hydrophobic polypeptoid: crystallization driven assembly transition from filaments to nanosheets. Macromolecules 2019, 52, $1546-1556$.

(52) Liu, G.; Dong, C.-M. Photoresponsive poly (S-(o-nitrobenzyl)l-cysteine)-b-PEO from a l-cysteine $\mathrm{N}$-carboxyanhydride monomer: synthesis, self-assembly, and phototriggered drug release. Biomacromolecules 2012, 13, 1573-1583.

(53) Kuhn, J. H.; Adachi, T.; Adhikari, N. K.; Arribas, J. R.; Bah, I. E.; Bausch, D. G.; Bhadelia, N.; Borchert, M.; Brantsæter, A. B.; BrettMajor, D. M. New filovirus disease classification and nomenclature. Nat. Rev. Microbiol. 2019, 17, 261-263.

(54) Leroy, E. M.; Kumulungui, B.; Pourrut, X.; Rouquet, P.; Hassanin, A.; Yaba, P.; Délicat, A.; Paweska, J. T.; Gonzalez, J.-P.; Swanepoel, R. Fruit bats as reservoirs of Ebola virus. Nature 2005, 438, 575-576.

(55) Messaoudi, I.; Amarasinghe, G. K.; Basler, C. F. Filovirus pathogenesis and immune evasion: insights from Ebola virus and Marburg virus. Nat. Rev. Microbiol. 2015, 13, 663-676.

(56) Zhang, K.; Rossin, R.; Hagooly, A.; Chen, Z.; Welch, M. J.; Wooley, K. L. Folate-mediated cell uptake of shell-crosslinked spheres and cylinders. J. Polym. Sci., Part A: Polym. Chem. 2008, 46, 75787583.

(57) Li, Z.; Sun, L.; Zhang, Y.; Dove, A. P.; O’Reilly, R. K.; Chen, G. Shape effect of glyco-nanoparticles on macrophage cellular uptake and immune response. ACS Macro Lett. 2016, 5, 1059-1064.

(58) Zhang, Z.; Liu, C.; Li, C.; Wu, W.; Jiang, X. Shape effects of cylindrical versus spherical unimolecular polymer nanomaterials on in vitro and in vivo behaviors. Research 2019, 2019, No. 2391486.

(59) Geng, Y.; Dalhaimer, P.; Cai, S.; Tsai, R.; Tewari, M.; Minko, T.; Discher, D. E. Shape effects of filaments versus spherical particles in flow and drug delivery. Nat. Nanotechnol. 2007, 2, 249-255.

(60) Xuan, S.; Gupta, S.; Li, X.; Bleuel, M.; Schneider, G. J.; Zhang, D. Synthesis and characterization of well-defined PEGylated polypeptoids as protein-resistant polymers. Biomacromolecules 2017, 18, 951-964. 


\title{
Supporting Information
}

\section{Thermoinduced crystallization-driven self-assembly of bioinspired}

\section{block copolymers in aqueous solution}

\author{
Zhiwei Wang, ${ }^{a \ddagger}$ Min Lin, ${ }^{a \neq}$ Colin Bonduelle, ${ }^{b}$ Rongye Li, ${ }^{a}$ Zhekun Shi, ${ }^{a}$ Chenhui Zhu, ${ }^{c}$ Sébastien \\ Lecommandoux, ${ }^{b^{*}}$ Zhibo Li, ${ }^{a^{*}}$, and Jing Sun ${ }^{a^{*}}$
}

\begin{abstract}
${ }^{a}$ Key Laboratory of Biobased Polymer Materials, College of Polymer Science and Engineering, Qingdao University of Science and Technology, Qingdao, 266042, China

${ }^{\mathrm{b}}$ Univ. Bordeaux, CNRS, Bordeaux INP, LCPO, UMR 5629, F-33600 Pessac, France

c Advanced Light Source, Lawrence Berkeley National Laboratory, Berkeley, California 94720, United States
\end{abstract}

\section{Table of Contents}

Table S1. Molecular parameters of all the polymers.

Table S2. DSC data for all the polymers.

Figure S1. GPC chromatograms of the polymers.

Figure S2. The DSC thermograms of all the polymers. 5

Figure S3. Plots of the transmittance versus temperature for aqueous solutions of PNAG- $g$-EG 3 .......... 5

Figure S4. Plots of the solution phase transition of both homopolymer and block copolymer 6

Figure S5. TEM images of (PNAG- $g-\mathrm{EG}_{3}$ )- $b$-PNOG stirred for $24 \mathrm{~h}$ at room temperature in aqueous solution 6

Figure S6. TEM images of the influence of stirring time and concentration on morphology 7

Figure S7. AFM images of the influence of incubation time on morphology 7 
Figure S8. AFM images of the influence of incubation temperature on morphology

Figure S9. TEM images of (PNAG- $\left.g-\mathrm{EG}_{3}\right)_{59}-b-\mathrm{PNOG}_{22}$ and (PNAG- $g$-EG 3 ) ${ }_{93}-b-\mathrm{PNOG}_{40}$ cylinderical morphology 9

Figure S10. AFM images of (PNAG- $\left.g-\mathrm{EG}_{3}\right)_{81}-b-\mathrm{PNOG}_{52}$ and (PNAG- $g$-EG 3$)_{102}-b-\mathrm{PNOG}_{49}$ nanosheet structure 9

Figure S11. ${ }^{1} \mathrm{H}$ NMR spectra of (PNAG-g-EG3) ${ }_{142}$-b-PNOG 23 labeled with fluorescein isothiocyanate (FITC) 10

Figure S12. Confocal laser scanning microscope images 10 


\section{Results and Discussion}

Table S1. Molecular parameters of all the polymers.

\begin{tabular}{|c|c|c|c|c|c|c|}
\hline Samples & $\begin{array}{l}\text { Feed } \\
\text { ratio }^{\text {[a] }}\end{array}$ & $\mathrm{m} / \mathrm{n}^{[\mathrm{b}]}$ & $\begin{array}{l}\mathrm{Mn}^{[\mathrm{c}]} \\
(\mathrm{kDa})\end{array}$ & $\begin{array}{l}\mathrm{Mn}^{[\mathrm{d}]} \\
(\mathrm{kDa})\end{array}$ & $\begin{array}{l}\text { Dispersity } \\
(Đ)^{[\mathrm{d}]}\end{array}$ & $\mathrm{X}_{\mathrm{PNOG}^{[\mathrm{e}]}}$ \\
\hline $\mathrm{PNOG}_{20}$ & 20 & 20 & 3.4 & 2.7 & 1.07 & - \\
\hline $\mathrm{PNAG}_{95}-g-\mathrm{EG}_{3}$ & 95 & 95 & 18.0 & 14.9 & 1.09 & - \\
\hline $\mathrm{PNAG}_{78}-g-\mathrm{EG}_{3}$ & 80 & 78 & 14.7 & 11.1 & 1.09 & \\
\hline $\mathrm{PNAG}_{59}-g-\mathrm{EG}_{3}$ & 60 & 59 & 11.2 & 8.8 & 1.06 & - \\
\hline $\mathrm{PNAG}_{81}-b-\mathrm{PNOG}_{52}$ & $95 / 60$ & $81 / 52$ & 16.6 & 12.4 & 1.16 & 0.39 \\
\hline $\begin{array}{c}\left(\text { PNAG- } g-\mathrm{EG}_{3}\right)_{81}-b- \\
\text { PNOG }_{52}\end{array}$ & - & $81 / 52$ & 24.1 & 18.5 & 1.18 & 0.39 \\
\hline $\mathrm{PNAG}_{102}-b-\mathrm{PNOG}_{49}$ & $100 / 50$ & $102 / 49$ & 18.1 & 15.6 & 1.06 & 0.32 \\
\hline $\begin{array}{c}\left(\text { PNAG- } g-\mathrm{EG}_{3}\right)_{102-} \\
b-\mathrm{PNOG}_{49}\end{array}$ & - & $102 / 49$ & 27.6 & 19.7 & 1.10 & 0.32 \\
\hline $\mathrm{PNAG}_{93}-b-\mathrm{PNOG}_{40}$ & $95 / 30$ & $93 / 40$ & 15.8 & 12.3 & 1.12 & 0.30 \\
\hline $\begin{array}{c}\left(\mathrm{PNAG}-g-\mathrm{EG}_{3}\right)_{93}-b- \\
\mathrm{PNOG}_{40}\end{array}$ & & $93 / 40$ & 24.3 & 18.6 & 1.15 & 0.30 \\
\hline $\mathrm{PNAG}_{59}-b-\mathrm{PNOG}_{22}$ & $60 / 30$ & $59 / 22$ & 9.4 & 8.6 & 1.18 & 0.27 \\
\hline $\begin{array}{c}\left(\mathrm{PNAG}-g-\mathrm{EG}_{3}\right)_{59}-b- \\
\text { PNOG }_{22}\end{array}$ & - & $59 / 22$ & 14.9 & 11.8 & 1.24 & 0.27 \\
\hline $\mathrm{PNAG}_{94}-b-\mathrm{PNOG}_{15}$ & $95 / 20$ & $94 / 15$ & 11.6 & 9.7 & 1.11 & 0.14 \\
\hline $\begin{array}{c}\left(\mathrm{PNAG}-g-\mathrm{EG}_{3}\right)_{94}-b- \\
\mathrm{PNOG}_{15}\end{array}$ & - & $94 / 15$ & 20.3 & 17.3 & 1.13 & 0.14 \\
\hline $\mathrm{PNAG}_{142}-b-\mathrm{PNOG}_{23}$ & $150 / 30$ & $142 / 23$ & 17.6 & 15.2 & 1.07 & 0.14 \\
\hline $\begin{array}{c}\left(\text { PNAG- } g-\mathrm{EG}_{3}\right)_{142-} \\
b-\mathrm{PNOG}_{23}\end{array}$ & - & $142 / 23$ & 30.7 & 21.2 & 1.09 & 0.14 \\
\hline
\end{tabular}

[a] Feed molar ratio of PEG / Oct-NCA; [b] Calculated from ${ }^{1} \mathrm{HNMR}$ spectra; [c] Calculated from ${ }^{1} \mathrm{HNMR}$ spectra;[d] Determined from GPC, [e] Mole fraction of PNOG. 
Table S2. DSC data for all the polymers.

\begin{tabular}{cccccc}
\hline Samples & $\Delta \mathrm{H}_{1}(\mathrm{~J} / \mathrm{g})$ & $\Delta \mathrm{H}_{2}(\mathrm{~J} / \mathrm{g})$ & $\mathrm{T}_{1}\left({ }^{\circ} \mathrm{C}\right)$ & $\mathrm{T}_{2}\left({ }^{\circ} \mathrm{C}\right)$ & $\mathrm{T}_{\mathrm{g}}\left({ }^{\circ} \mathrm{C}\right)$ \\
\hline $\mathrm{PNAG}_{95}-\mathrm{g}-\mathrm{EG}_{3}$ & - & - & - & - & 53.0 \\
$\mathrm{PNOG}_{20}$ & 12.3 & 25.2 & 50.8 & 163.5 & - \\
$\left(\mathrm{PNAG}_{-} \mathrm{g}-\mathrm{EG}_{3}\right)_{81}-b-\mathrm{PNOG}_{52}$ & 7.4 & 9.2 & 46.7 & 150.8 & - \\
$\left(\mathrm{PNAG}-\mathrm{g}-\mathrm{EG}_{3}\right)_{102}-b-\mathrm{PNOG}_{49}$ & 3.0 & 2.7 & 46.8 & 147.6 & - \\
$\left(\mathrm{PNAG}-\mathrm{g}-\mathrm{EG}_{3}\right)_{93}-b-\mathrm{PNOG}_{40}$ & 2.6 & 1.7 & 56.0 & 104.3 & - \\
$\left(\mathrm{PNAG}-\mathrm{g}-\mathrm{EG}_{3}\right)_{59}-b-\mathrm{PNOG}_{22}$ & 5.5 & - & 60.5 & - & - \\
$\left(\mathrm{PNAG}-\mathrm{g}-\mathrm{EG}_{3}\right)_{142}-b-\mathrm{PNOG}_{23}$ & 4.2 & - & 60.9 & - & - \\
$\left(\mathrm{PNAG}-\mathrm{g}-\mathrm{EG}_{3}\right)_{94}-b-\mathrm{PNOG}_{15}$ & 2.3 & - & 53.3 & - & - \\
\hline
\end{tabular}

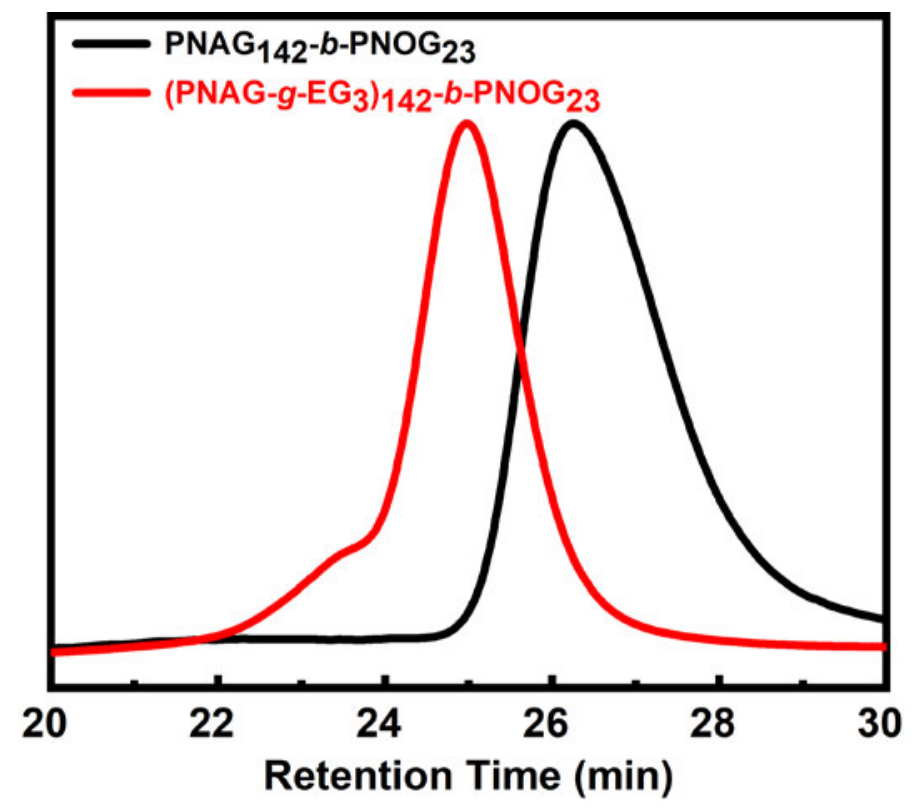

Figure S1. GPC chromatograms of the polymers. The molecular characteristics are shown in Table S1. 


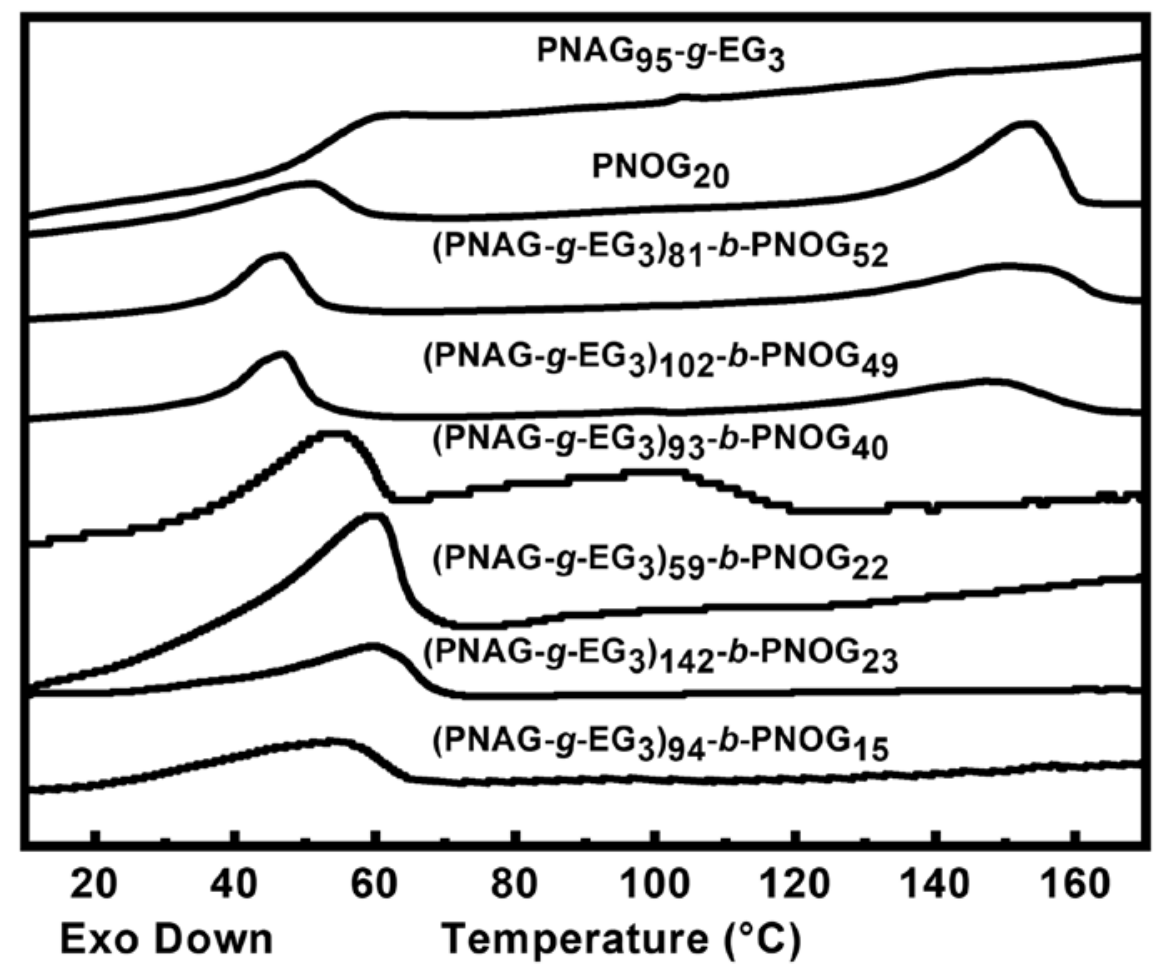

Figure S2. The DSC thermograms of all the polymers. The detailed information is summarized in Supplementary Table 2.

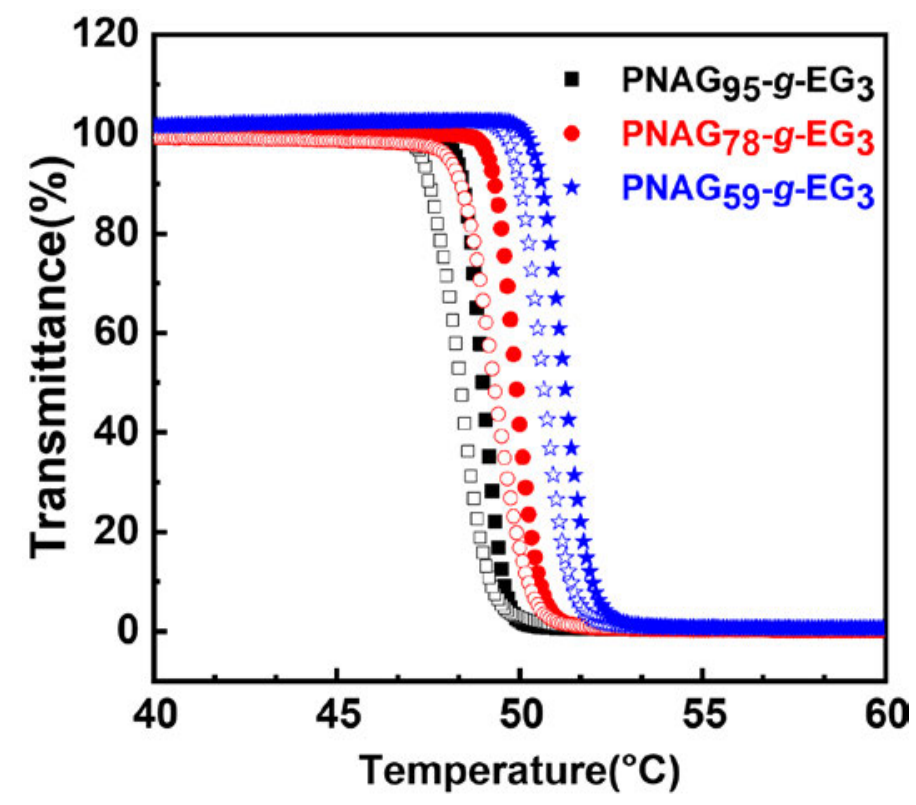

Figure S3. Plots of the transmittance versus temperature for aqueous solutions of PNAG-g-EG 3 at a concentration of 5 $\mathrm{mg} / \mathrm{mL}$. Filled symbol: heating ramp, open symbol: cooling ramp. 
(a)

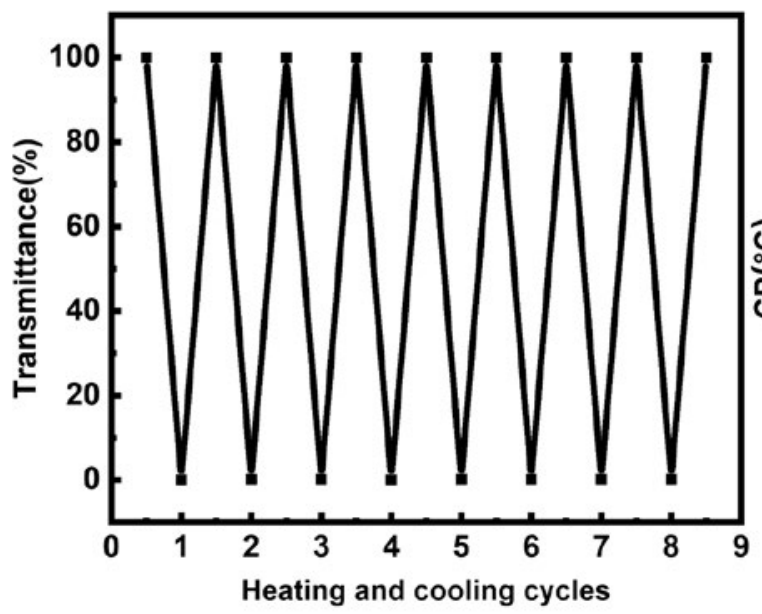

(b)

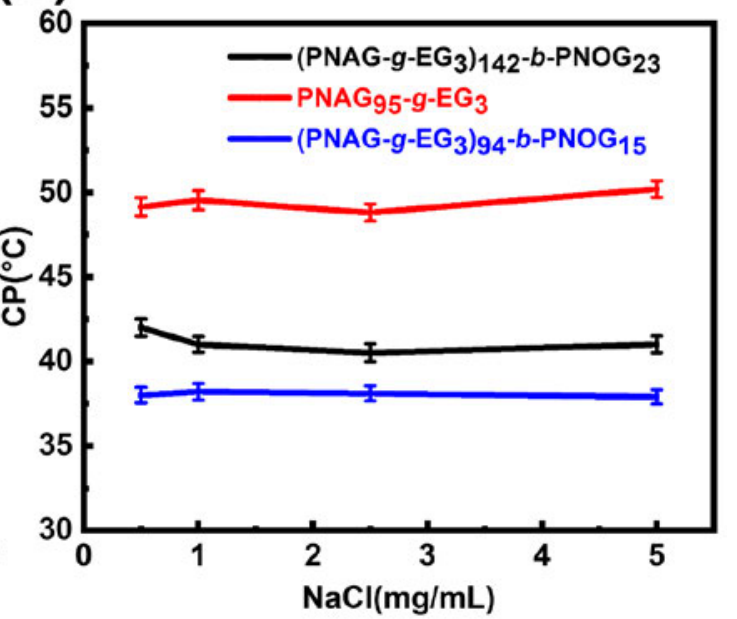

Figure S4. (a) Transmittance of (PNAG- $\left.g-\mathrm{EG}_{3}\right)_{142}-b-\mathrm{PNOG}_{23}, \mathrm{PNAG}_{95}-g-\mathrm{EG}_{3}$ and $\left(\mathrm{PNAG}-g-\mathrm{EG}_{3}\right)_{94}-b-\mathrm{PNOG}_{15}$ aqueous solution at a concentration of $5 \mathrm{mg} / \mathrm{mL}$ versus 8 heating and cooling cycles between 30 and $60^{\circ} \mathrm{C}$. (b) Plots of $\mathrm{CP}$ as a function of $\mathrm{NaCl}$ concentration for (PNAG- $\left.g-\mathrm{EG}_{3}\right)_{142}-b-\mathrm{PNOG}_{23}, \mathrm{PNAG}_{95}-g-\mathrm{EG}_{3}$ and (PNAG-g-EG $)_{94}-b$ $\mathrm{PNOG}_{15}$ solution at a concentration of $5 \mathrm{mg} / \mathrm{mL}$.
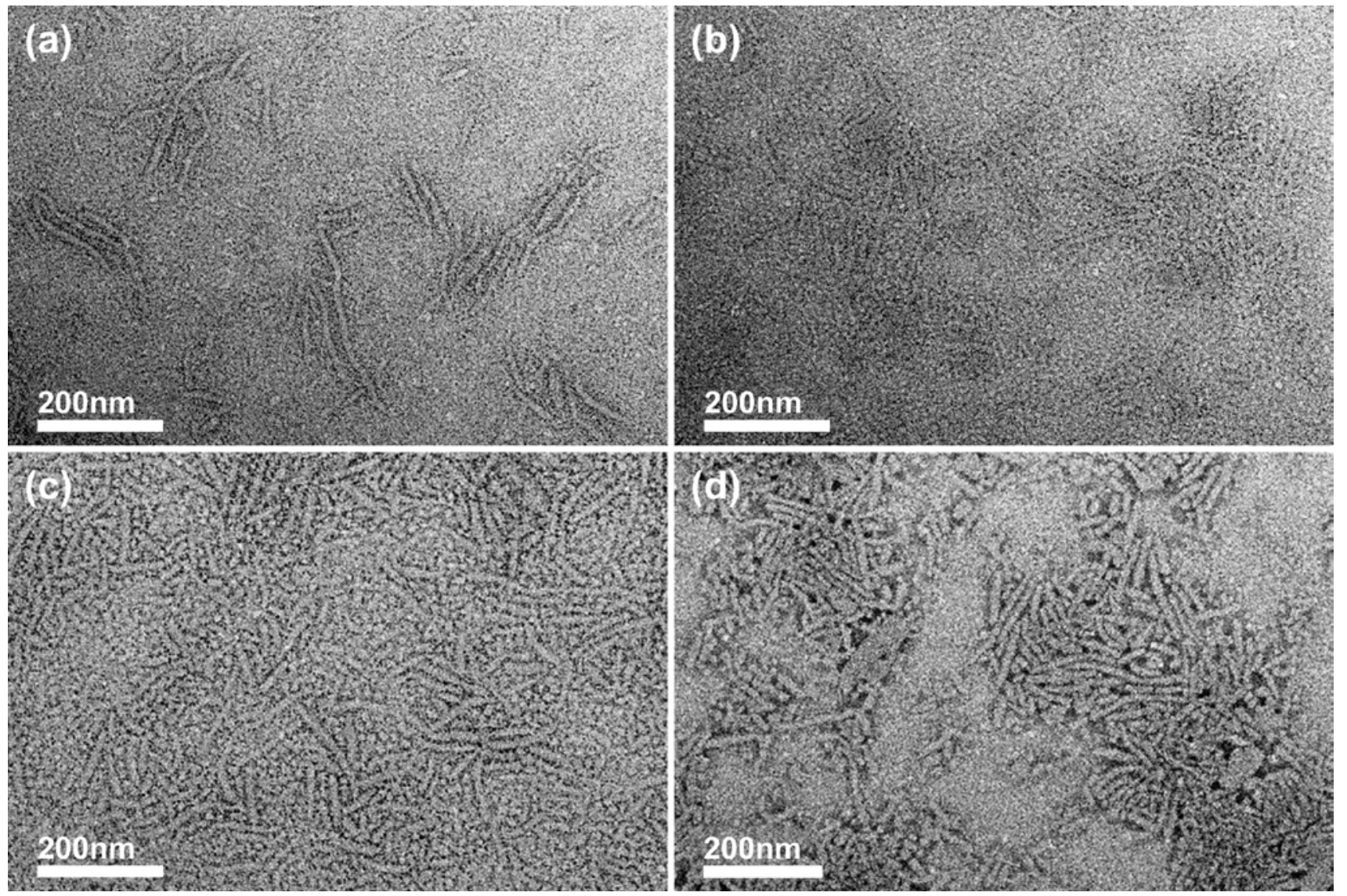

Figure S5. TEM images of (PNAG- $\left.g-\mathrm{EG}_{3}\right)_{59}-b-\mathrm{PNOG}_{22}(\mathrm{a}),\left(\mathrm{PNAG}-g-\mathrm{EG}_{3}\right)_{93}-b-\mathrm{PNOG}_{40}(\mathrm{~b}),\left(\mathrm{PNAG}-g-\mathrm{EG}_{3}\right)_{102}-b-$ $\mathrm{PNOG}_{49}(\mathrm{c})$ and $\left(\mathrm{PNAG}_{-}-\mathrm{EG}_{3}\right)_{81}-b-\mathrm{PNOG}_{52}$ (d) stirred for $24 \mathrm{~h}$ at room temperature in aqueous solution at a concentration of $1 \mathrm{mg} / \mathrm{mL}$. 

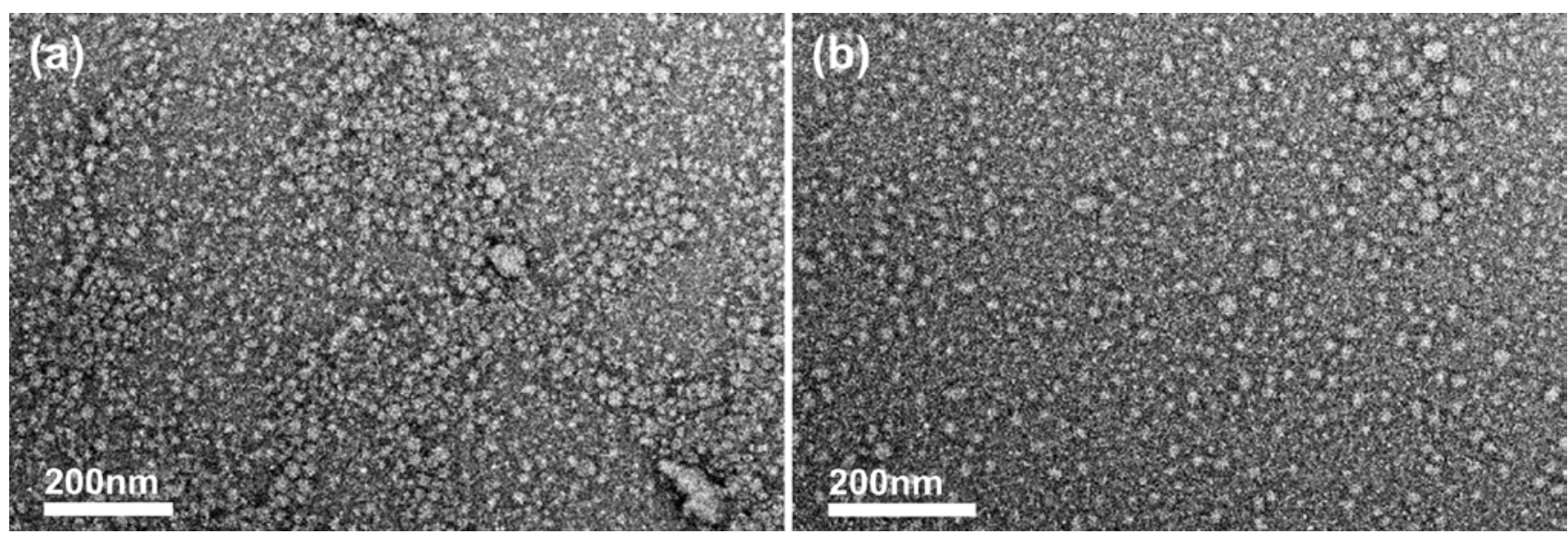

Figure S6. TEM images of (PNAG- $\left.g-\mathrm{EG}_{3}\right)_{142}-b-\mathrm{PNOG}_{23}$ stirred for 5 days at room temperature in aqueous solution at a concentration of $1 \mathrm{mg} / \mathrm{mL}$ (a) and $5 \mathrm{mg} / \mathrm{mL}$ (b).
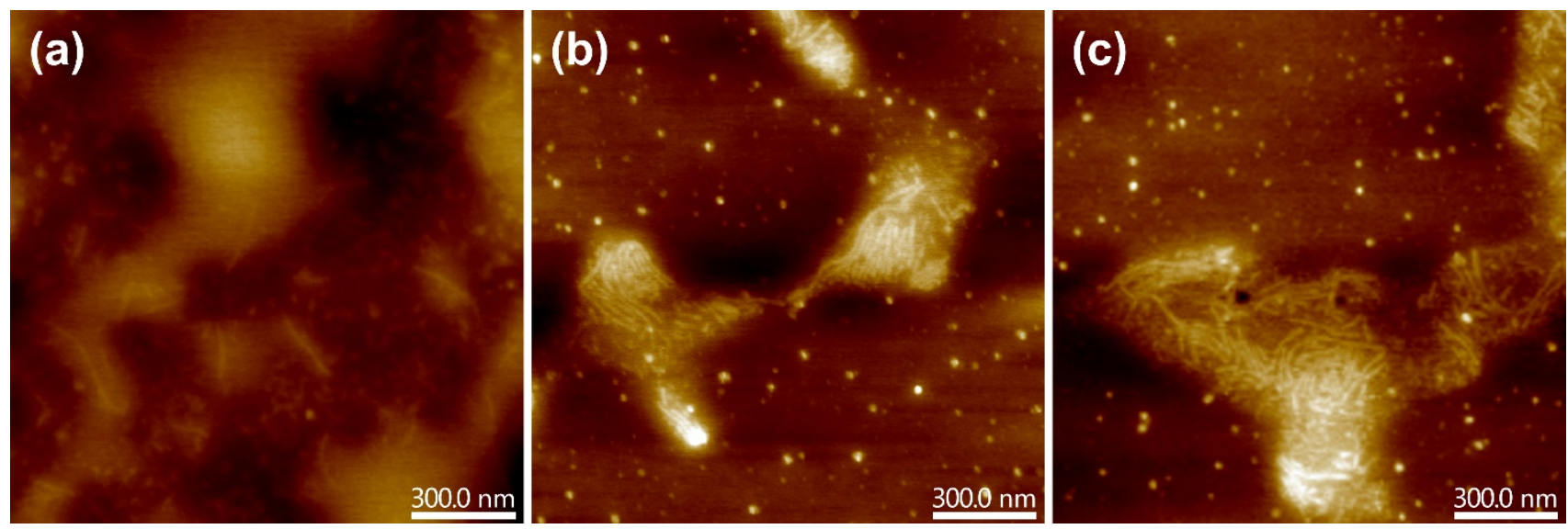

Figure S7. AFM images of (PNAG-g-EG 3$)_{142}-b$-PNOG $_{23}$ incubated at $60^{\circ} \mathrm{C}$ for $1 \mathrm{~h} \mathrm{(a),} 2 \mathrm{~h}$ (b) and $3 \mathrm{~h}(\mathrm{c})$ after stirring for $24 \mathrm{~h}$ at room temperature in aqueous solution at a concentration of $1 \mathrm{mg} / \mathrm{mL}$. 

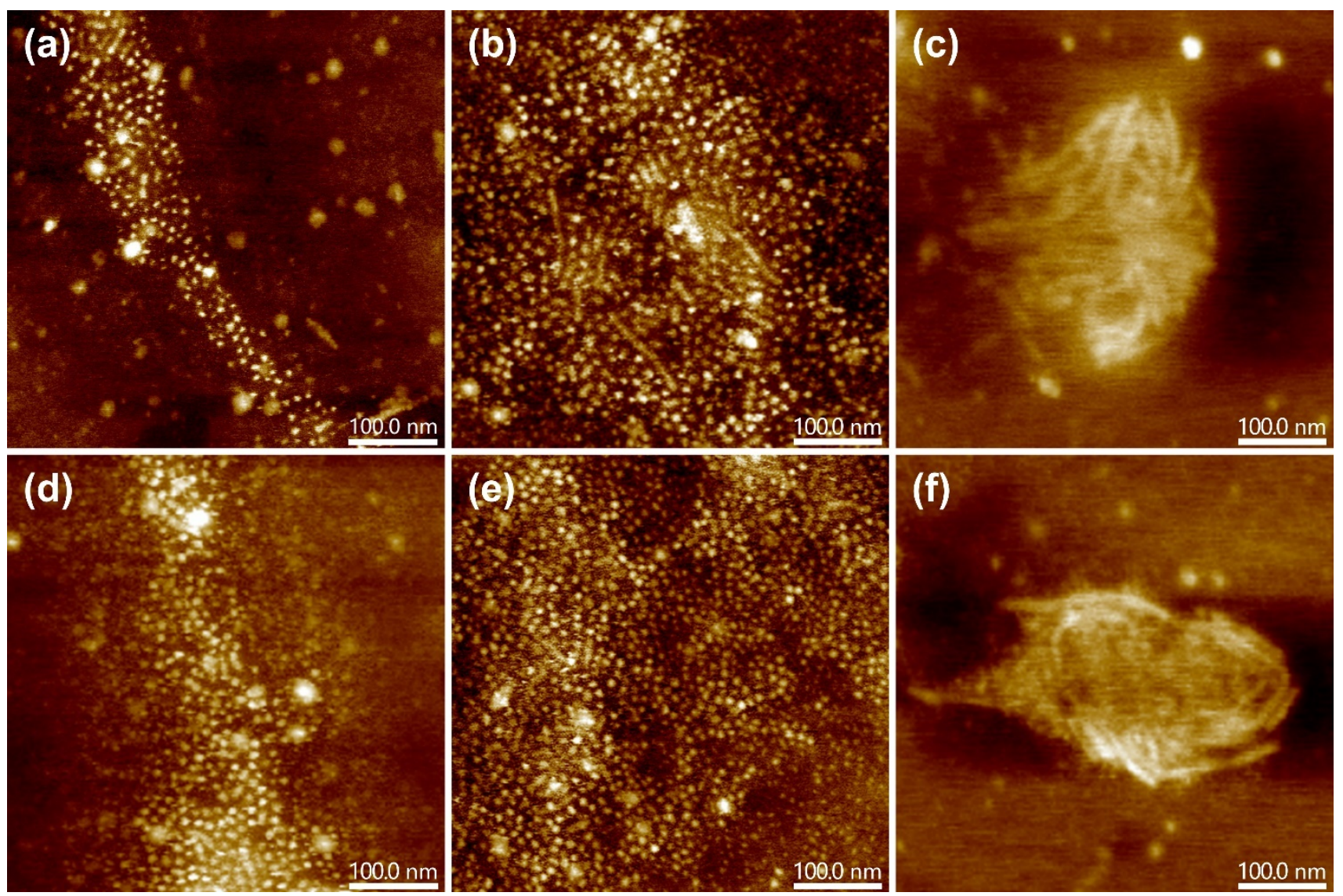

Figure S8. AFM images of (PNAG-g-EG $)_{142}-b-\mathrm{PNOG}_{23}$ incubated at $40{ }^{\circ} \mathrm{C}$ (a), $50^{\circ} \mathrm{C}$ (b) and $80^{\circ} \mathrm{C}$ (c) for $2 \mathrm{~h}$ after stirring for $24 \mathrm{~h}$ at room temperature in aqueous solution at a concentration of $1 \mathrm{mg} / \mathrm{mL}$. AFM images of assemblies (d), (e) and (f) after cooling solution of (a), (b) and (c) to the room temperature, respectively. 

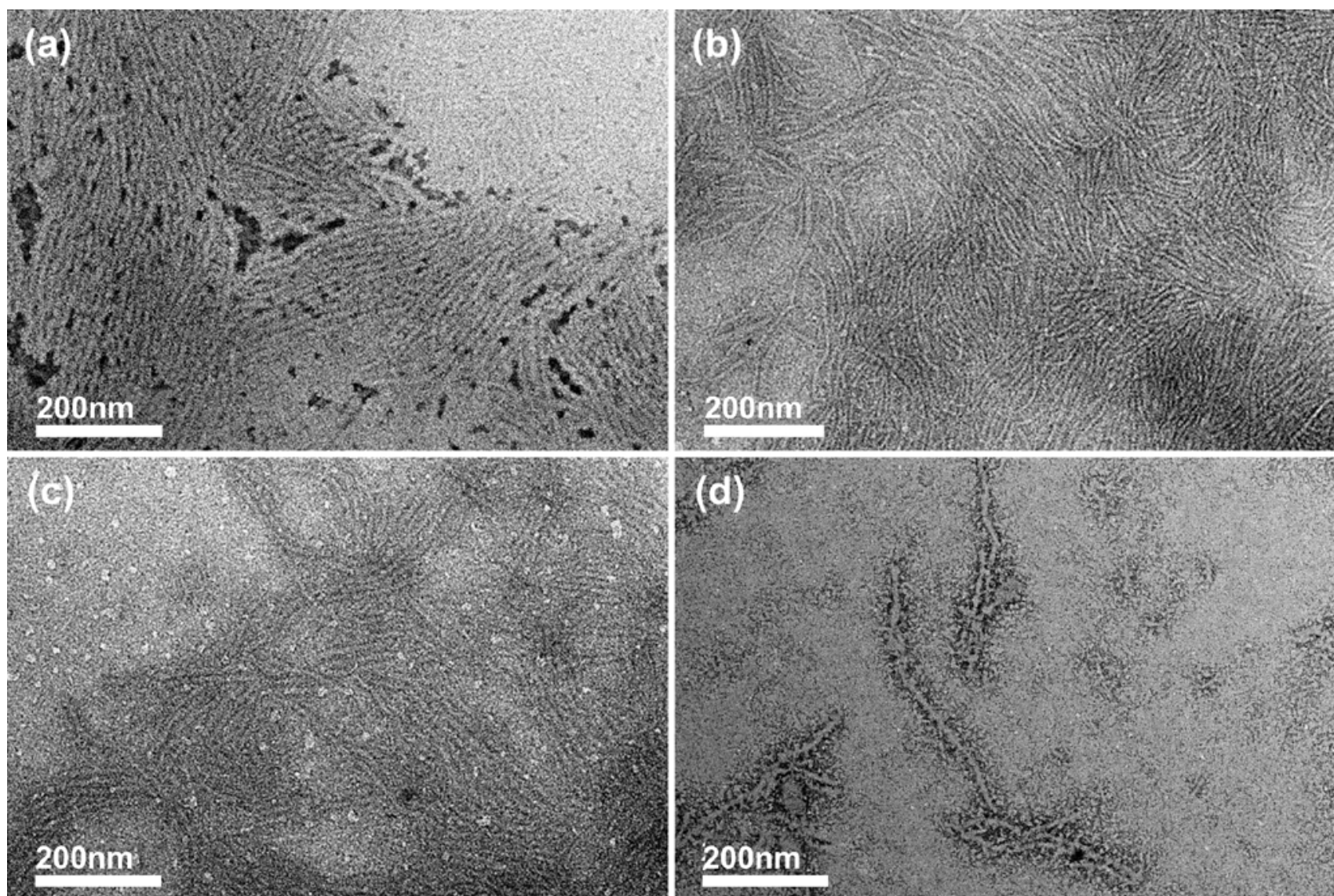

Figure S9. TEM images of (PNAG- $\left.g-\mathrm{EG}_{3}\right)_{59}-b-\mathrm{PNOG}_{22}(\mathrm{a}),\left(\mathrm{PNAG}-g-\mathrm{EG}_{3}\right)_{93}-b-\mathrm{PNOG}_{40}$ (c), incubated at $60{ }^{\circ} \mathrm{C}$ for 2 $\mathrm{h}$ after stirring for $24 \mathrm{~h}$ at room temperature in aqueous solution at a concentration of $1 \mathrm{mg} / \mathrm{mL}$. TEM images of (PNAG$\left.g-\mathrm{EG}_{3}\right)_{59}-b-\mathrm{PNOG}_{22}$ (b), (PNAG- $\left.g-\mathrm{EG}_{3}\right)_{93}-b-\mathrm{PNOG}_{40}$ (d) after cooling the solutions in (a) and (c) to the room temperature, respectively.
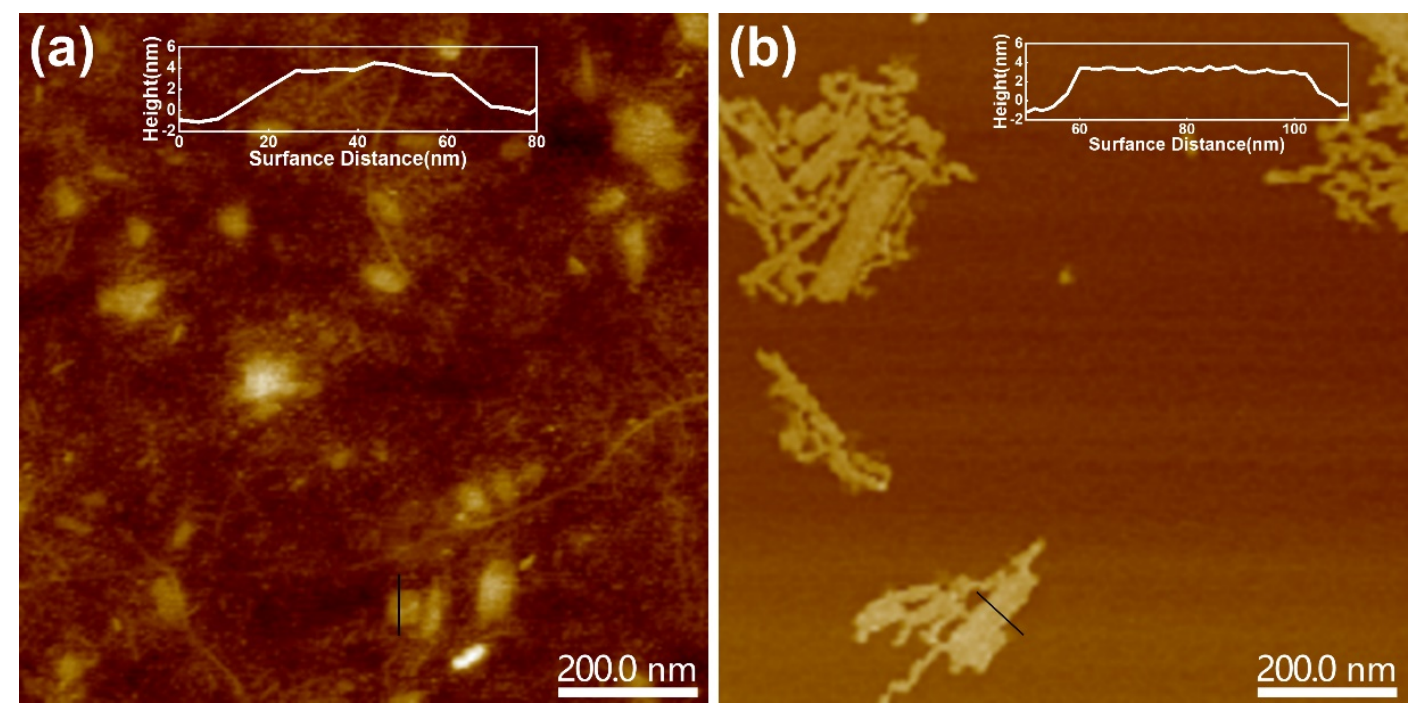

Figure S10.AFM images of (PNAG-g-EG 3$)_{81}-b-$ PNOG $_{52}$ (a) and (PNAG- $\left.g-\mathrm{EG}_{3}\right)_{102}-b-\mathrm{PNOG}_{49}$ (b) incubated at $60{ }^{\circ} \mathrm{C}$ for $2 \mathrm{~h}$ after stirring for $24 \mathrm{~h}$ at room temperature in aqueous solution at a concentration of $1 \mathrm{mg} / \mathrm{mL}$. 


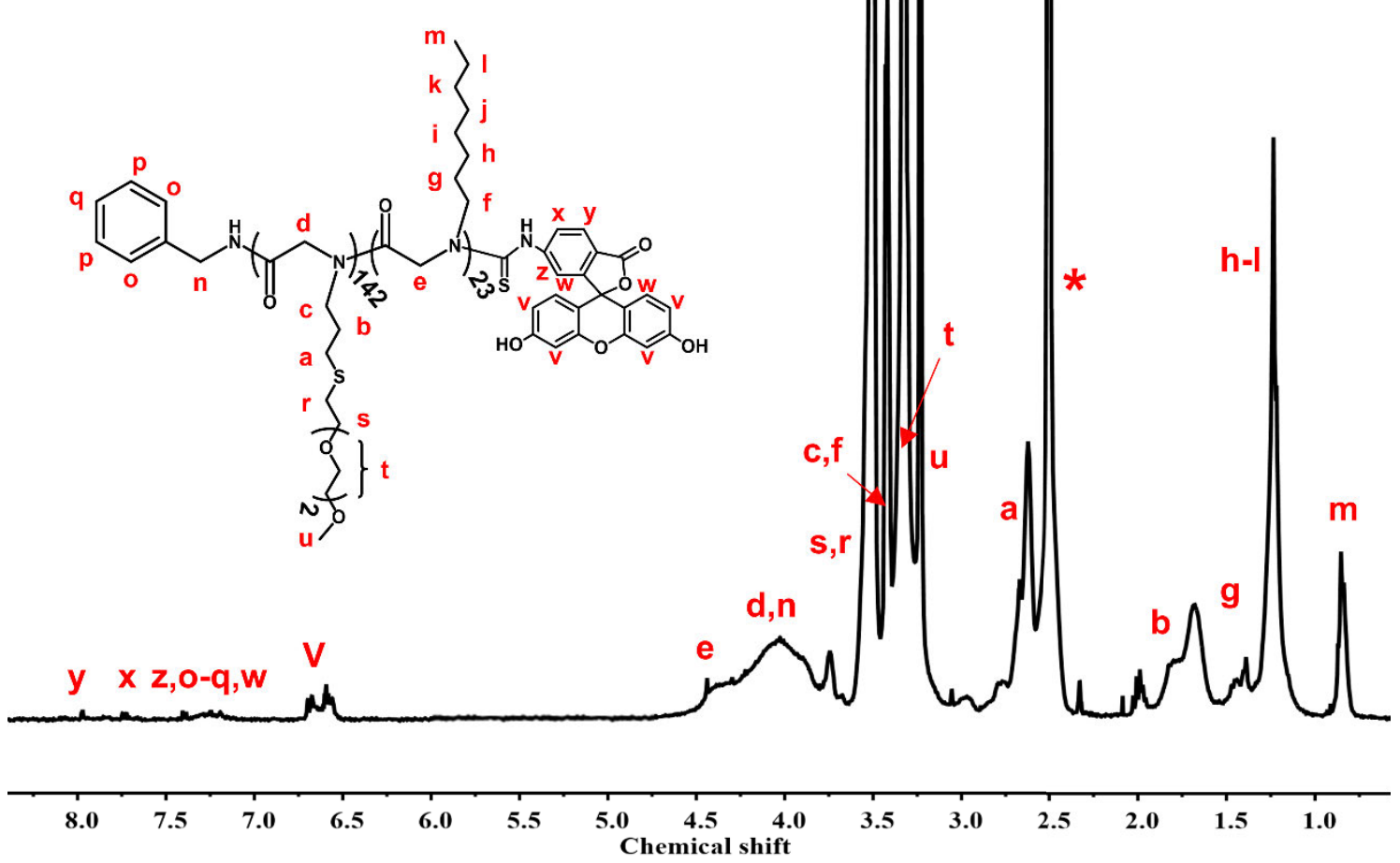

Figure S11. ${ }^{1} \mathrm{H}$ NMR spectra of (PNAG-g-EG3) ${ }_{142}-\mathrm{b}-\mathrm{PNOG}_{23}$ labeled with fluorescein isothiocyanate (FITC) quantitatively in DMSO- $d_{6}\left(*\right.$ indicates DMSO- $\left.d_{6}\right)$.
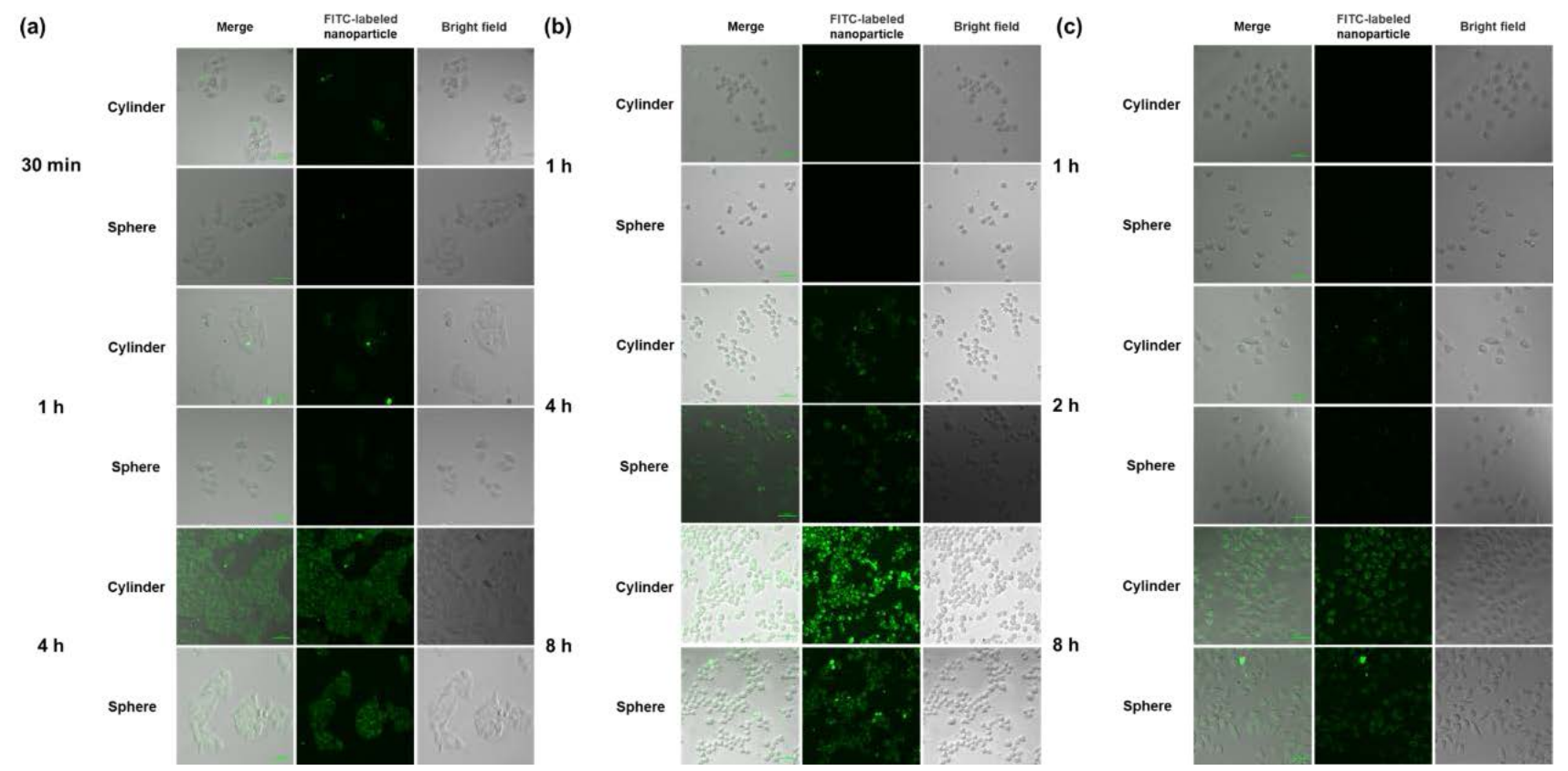

Figure S12. Confocal laser scanning microscope images of Hela cells (a), RAW264.7 (b) and L929 (c) cells incubated with FITC-labeled assemblies at a concentration of $0.5 \mathrm{mg} / \mathrm{ml}$ for different incubation time at $37^{\circ} \mathrm{C}$. Scale bars $=50 \mu \mathrm{m}$. 